\title{
Seismic Performance of CAP1400 Nuclear Power Station considering Foundation Uplift
}

\author{
Ling-Yun Peng $\mathbb{D},{ }^{1}$ Ying-Jie Kang $\mathbb{D}^{1},{ }^{1}$ Zhen-Yun Tang $\mathbb{D}^{1},{ }^{1}$ and Hua-Ting Chen $\mathbb{D}^{2}$ \\ ${ }^{1}$ Beijing Key Lab of Earthquake Engineering and Structural Retrofit, Beijing University of Technology, Beijing 100124, China \\ ${ }^{2}$ Earthquake Engineering Research \& Test Center, Guangzhou University, Guangzhou 510405, China \\ Correspondence should be addressed to Ling-Yun Peng; ply@bjut.edu.cn
}

Received 18 October 2017; Revised 13 February 2018; Accepted 7 March 2018; Published 12 April 2018

Academic Editor: Lutz Auersch

Copyright (c) 2018 Ling-Yun Peng et al. This is an open access article distributed under the Creative Commons Attribution License, which permits unrestricted use, distribution, and reproduction in any medium, provided the original work is properly cited.

\begin{abstract}
Under earthquake action, the reinforced concrete structure at the edge of the CAP1400 nuclear power plant foundation slab will be uplifted. In order to determine the seismic performance of this structure, a 1:12 scale shaking table test model was fabricated using gypsum as simulated concrete in order to meet scaled design requirements. By testing this model, the seismic response of the structure with consideration of the foundation uplift was obtained. Numerical analyses of the test model and the prototype structure were conducted to gain a better understanding of the structural seismic performance. When subjected to earthquakes, the foundation slab of the nuclear power plant experiences a slight degree of uplift but remains in the elastic stage due to the weight of the structure above, which provides an antioverturning moment. The numerical simulation is in general agreement with the test results, suggesting numerical simulations could be accurately employed in place of physical tests. The superstructure displacement response was found not to affect the safety of adjacent structures, and the seismic performance of the structure was shown to meet the relevant design requirements, demonstrating that this approach to modelling can serve as a design basis for the CAP1400 nuclear power demonstration project.
\end{abstract}

\section{Introduction}

During natural disasters, nuclear power plants can be severely damaged, and this damage can lead to even more harmful secondary disasters, such as the 2011 Fukushima nuclear accident in Japan, which resulted in huge social and economic losses [1]. The seismic safety of a nuclear power plant structure is critical in ensuring the safe production of nuclear power, but the appropriate degree of safety remains a critical facet of design to be improved $[2,3]$. The CAP1400 nuclear power plant is representative of a new generation of nuclear power technology, intended to lead the future mainstream development of large-scale nuclear power. Accordingly, the seismic performance of this demonstration reactor must be based on strict design standards [4]. The CAP1400 nuclear power plant is designed using raft foundations, which provide a separation between the "nuclear island" and the "conventional island," in accordance with the requirements of functional isolation, as can be seen in Figure 1. A facility, hereinafter referred to as the first span structure, is located at the edge of the conventional island foundation slab, adjacent to the nuclear island. The structural seismic rating of this first span was increased from that for nonseismic items to that for nuclear class II seismic items in the AP1000 nuclear power plant, indicating that the structural seismic capacity should be increased. Previous earthquake disasters show that strong seismic action often causes parts of a structure foundation to uplift, separating the foundation from the ground [5-7]. Additionally, some equipment, furniture, and other noncivil structures can vibrate and even be overturned [8]. Under earthquake action, the separate foundation slabs of the CAP1400 nuclear power plant also have a tendency to uplift, which has a direct effect on the seismic safety of the overall nuclear power plant.

In previous studies, to quantify the seismic uplift, a singlelayer and a multilayer system that considered the foundation uplift were simplified as a mechanical models fixed on a rigid foundation $[7,9]$. Under rocking vibration, the foundation uplift and elastic deformation of the superstructure have been observed to influence each other [10]. Using a shaking table 


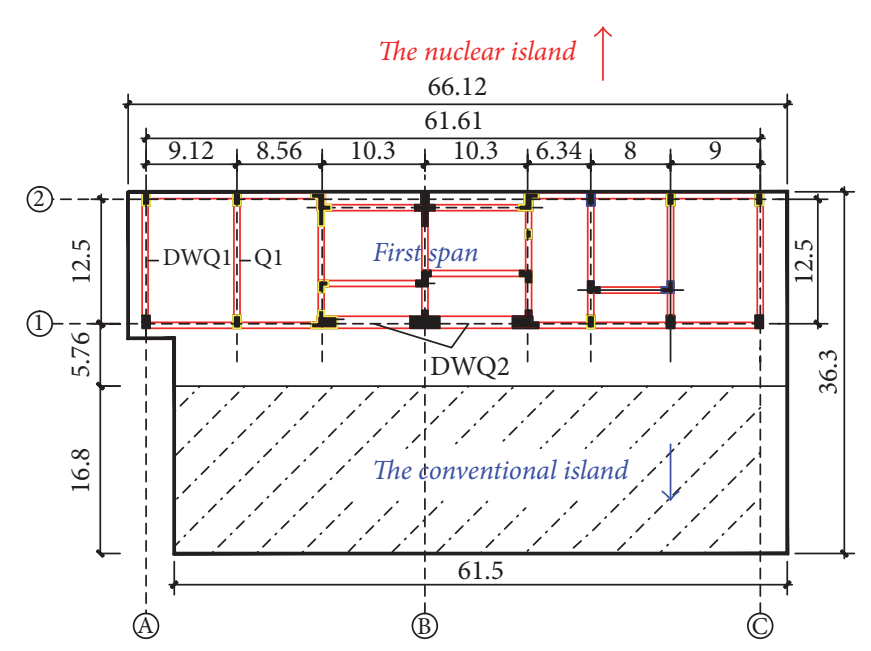

(a) Plan of the subject structure (m)

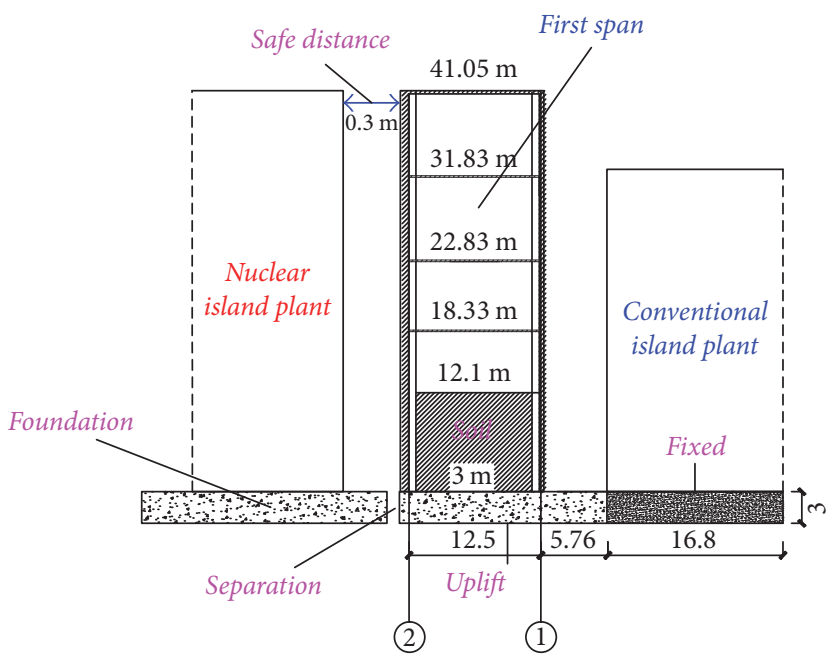

(b) Profile of the subject structure (m)

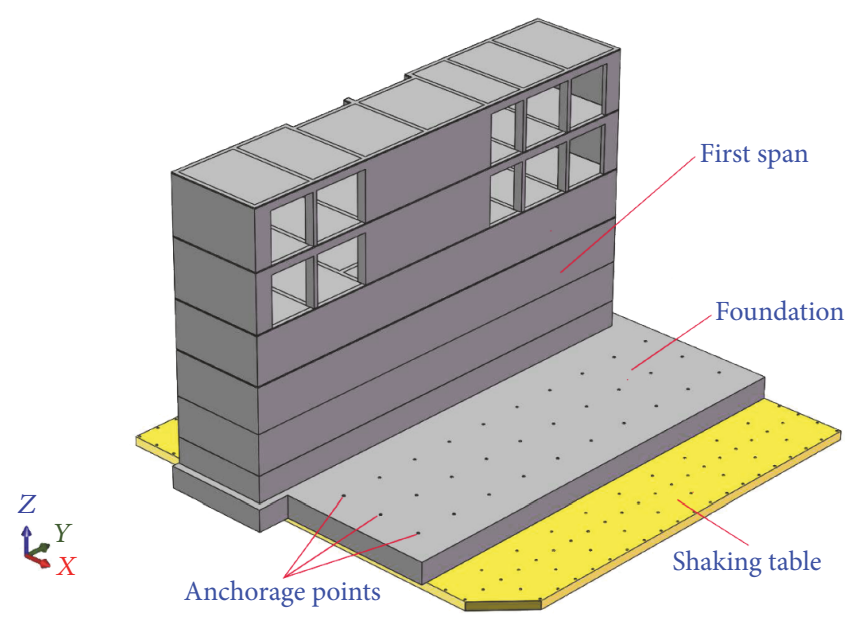

(c) 3-dimensional graphic of the test structure model

FIGURE 1: First span subject structure diagrams.

test and numerical simulation, the oscillation response of a single rigid body under base excitation has been obtained [11]. The single rigid body rocking response when fixed on a rigid foundation slab has also been studied [12]. The main effects of uplift of the structural foundation have been observed as follows: when the foundation slab undergoes uplift, it interacts with the base of the structure; structural foundation uplift is directly related to the overturning resistance of the structure; the uplift of the foundation has an obvious influence on the seismic response of the structure, and, under certain conditions, the damage to buildings subject to strong earthquakes may be reduced by uplift [13-17]. Notably, in previous research, the foundation slab is considered to be a rigid body in order to investigate the soil-foundation-structure interaction. However, little research has been conducted on a particular case in which one end of the foundation slab is restrained and the other end can be raised as a result of seismic response.

In this paper, the first span of the CAP1400 nuclear power plant and its foundation slab were used as test subjects. A shaking table test model, taking into consideration factors such as foundation uplift, material nonlinearity, and local foundation restraint, was constructed with gypsum, which serves as a scale-appropriate material similar to concrete. The seismic responses of the structure with foundation uplift when subjected to different levels of earthquake excitation were then recorded. At the same time, the ABAQUS software package was used to analyze the experimental model, and the results of the shaking table test and this numerical simulation were compared. Then, the seismic performance of the structure was evaluated by using an overturning analysis of the CAP1400 nuclear power plant structure to provide a design basis for the CAP1400 demonstration nuclear power plant. Finally, time history analysis for the prototype structure model was performed to further obtain the seismic performance of the building.

\section{Means and Methods}

2.1. Prototype Structure Description. As shown in Figure 1, the first span structure is located between the conventional island 
and the nuclear island in the CAP1400 nuclear power station. The first span structure consists of a single span structure in its weak-axis direction, in which the basement as well as the first and second floors is constructed of reinforced concrete shear walls, and the third and fourth floors are constructed of framed shear walls. The footprint of the structure is 12.5 $\times 61.61 \mathrm{~m}$, with a two-story basement of $9.1 \mathrm{~m}$ depth in total and four aboveground stories of $28.95 \mathrm{~m}$ height in total. The basement is filled with backfill. The thickness of main walls Q1 and DWQ1 is $600 \mathrm{~mm}$, and the thickness of local wall DWQ2 is $1200 \mathrm{~mm}$. The main structural materials are C40 concrete and HRB400 steel reinforcing bar. The first span is located on a $3 \mathrm{~m}$ thick raft foundation slab forming the main structure of the conventional steam engine room, but the first span is not connected to the upper structure of the steam engine room due to functional isolation requirements. The raft foundation only extends $100 \mathrm{~mm}$ beyond the edge of the span structure and is separated from the foundation slab of the nuclear island, as shown in Figure 1(b). Considering the strong constraint offered by the surrounding soil, the conventional island would not be uplifted, and it imposes a constraint on the first span structure. As the first span is quite close to the nuclear island plant (a net distance of only $300 \mathrm{~mm}$ ), the structural design of the first span foundation must ensure that the seismic performance of this structure does not affect the safety of the adjacent nuclear island facilities. The first span is designed according to seismic fortification intensity VIII ( $0.3 \mathrm{~g})$ of the Chinese building code [18]. In elastoplastic time history analysis, the design seismic waves coincide with the RG1.60 spectrum calibrated by $0.5 \mathrm{~g}$ [19]. When the structure is subjected to seismic action, the foundation slab should be able to withstand the overturning moment. In this study, the first span structure and the foundation slab are analyzed as an integral structure.

2.2. Model Design. The dimensions of the shaking table used, which could produce motion in all three directions, were $5 \times$ $5 \mathrm{~m}$. The maximum acceleration of the shaking table was $2.5 \mathrm{~g}$ in the horizontal direction with a maximum proof mass of $30 \mathrm{t}$, where $\mathrm{g}$ is the gravitational acceleration. The frequency of the input motion ranged from 0.1 to $50 \mathrm{~Hz}$. The entire structure, including the building and the foundation, was the prototype structure of the shaking table test. In the shaking table test that considers foundation uplift, the weight of the structure acts to resist overturning. The coupling action of vertical and horizontal forces must therefore be taken into consideration [20]. The force equilibrium relationship of the structure under vertical gravity is

$$
m g+k x=0
$$

where $m, k$, and $x$ are the quality, stiffness, and displacement of the structure; $g$ is the gravitational acceleration.

The scaling factor relationship conforms to dimension theory, so the similitude equilibrium is

$$
S_{\rho} S_{L}^{3} S_{g}+S_{E} S_{L}^{2}=0
$$

There is

$$
\frac{S_{E}}{S_{\rho} S_{g} S_{L}}=1,
$$

where $S_{E}$ is the scaling factor of Young's modulus, $S_{\rho}$ is the scaling factor of equivalent mass density, $S_{g}$ is the scaling factor of gravitational acceleration, and $S_{L}$ is the scaling factor of dimension.

The force equilibrium relationship of the structure under the action of horizontal earthquake is

$$
m\left(\ddot{x}+\ddot{x}_{g}\right)+c \dot{x}+k x=0,
$$

where $\ddot{x}$ and $\dot{x}$ are acceleration and velocity of the structure; $\ddot{x}_{g}$ is the earthquake acceleration; $c$ is the structure damping coefficient.

Thus, based on the dimensional analysis method, the similitude equilibrium is

$$
S_{\rho} S_{L}^{3}\left(S_{a}+S_{a}\right)+S_{E} S_{L}^{2}+S_{E} S_{L}^{2}=0 .
$$

There is

$$
\frac{S_{E}}{S_{\rho} S_{a} S_{L}}=1,
$$

where $S_{a}$ is the scaling factor of horizontal acceleration.

Accordingly, the requirements of (3) and (6) must be simultaneously satisfied to consider the coupling action of vertical and horizontal forces. Because the gravitational acceleration of the structure is difficult to change in a shaking table test, $S_{g}$ and $S_{a}$ are set to 1 . Taking the dimensions of the shaking table into account, the value of $S_{L}$ is set to $1 / 12$. The weight of the structure to be modelled is approximately 39,537 tons. If the test model is constructed of the same concrete material as the subject structure, that is, $S_{E}$ is set to 1 , the total weight of the test model would be 274.6 tons, which is much heavier than the bearing capacity of the shaking table. If $S_{L}$ is reduced to $1 / 35$, the total weight of the test model is reduced to 32.27 tons, which is still greater than the ultimate bearing capacity of the shaking table. Additionally, a smaller scaled length would significantly increase the difficulty of constructing the test model and also increase behavioral variability due to the size effect.

In order to reduce the weight of the model, comply with the bearing capacity of the shaking table, and provide similar material and design parameters for the model, scaled Young's modulus $S_{E}$ is set to $1 / 12$, allowing for the use of gypsum, which has a low elastic modulus and low strength but is a lighter material than concrete, reducing the total weight of the model to 22.88 tons, well within the bearing capacity of the shaking table. The detailed scaling coefficients can be seen in Table 1 .

The use of gypsum has been studied in a centrifuge shaking table test [21]. A similar material for a shaking table model test of a large underground cavern group was obtained by conducting a similar material ratio test using rock [22]. Based on the theorem of Buckingham's $\pi$, a $1 / 20$ scale model of the concrete containment shell of the CPR1000 nuclear power 
TABLE 1: Detailed similarity coefficients.

\begin{tabular}{lcr}
\hline Physical quantity & Dimension & Scaling coefficient \\
\hline Size & {$[\mathrm{L}]$} & $S_{L}=1 / 12$ \\
Young's modulus & {$\left[\mathrm{FL}^{-2}\right]$} & $S_{E}=1 / 12$ \\
Strain & - & $S_{\varepsilon}=1$ \\
Stress & {$\left[\mathrm{FL}^{-2}\right]$} & $S_{\sigma}=1 / 12$ \\
Effective mass density & {$\left[\mathrm{FL}^{-4} \mathrm{~T}^{2}\right]$} & $S_{\rho}=1$ \\
Time & {$[\mathrm{T}]$} & $S_{T}=0.289$ \\
Frequency & {$\left[\mathrm{T}^{-1}\right]$} & $S_{\omega}=3.464$ \\
Acceleration & {$\left[\mathrm{LT}^{-2}\right]$} & $S_{a}=1$ \\
\hline
\end{tabular}

TABLE 2: Mix proportion and material properties.

\begin{tabular}{|c|c|c|c|c|c|}
\hline \multicolumn{6}{|c|}{ Mix proportion } \\
\hline Gypsum & Mineral powder & Fiber & Water & Retarder & Water reducer \\
\hline 1 & 0.55 & 0.0025 & 0.5 & $0.005 \%$ & $1 \%$ \\
\hline \multicolumn{6}{|c|}{ Material properties } \\
\hline Density & Young's & & \multicolumn{2}{|c|}{ Compressive strength } & Bending strength \\
\hline $1800 \mathrm{~kg} / \mathrm{m}^{3}$ & 276 & & \multicolumn{2}{|c|}{$3.8 \mathrm{Mpa}$} & $0.85 \mathrm{Mpa}$ \\
\hline
\end{tabular}

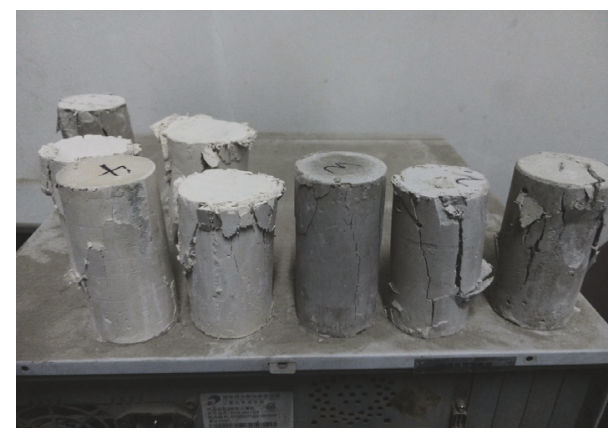

FIGURE 2: Typical compressive fracture failure modes.

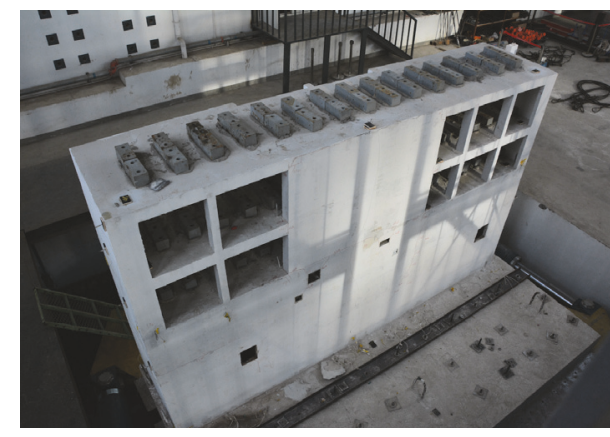

FIgURE 3: Counterweighting the test model. plant was constructed using a cement mortar material [23]. These research results indicate that the use of a concrete simulation material can meet all experimental requirements through a material proportioning test. Accordingly, gypsum was used as the experimental model material, and the appropriate proportions of gypsum were determined by experiment. In order to improve the mechanical properties of the gypsum, some additives were included. The main components of the gypsum mix included gypsum, mineral powder, fiber, water, retarder, and water reducing agent, in the material ratios shown in Table 2 . The density, Young's modulus, and compressive strength of the gypsum are $1800 \mathrm{~kg} / \mathrm{m}^{3}$, $2765 \mathrm{MPa}$, and $3.8 \mathrm{MPa}$, respectively. The scale of Young's modulus $S_{E}$ between the gypsum and the original model concrete is $1 / 12$, which meets the design requirements for the test. Figure 2 shows the typical compressive failure modes of the gypsum test blocks.

The reinforcement ratios of the model sections were calculated according to the principle of equivalent bearing capacity. The control of the normal section bearing capacity is based on the principle of equivalent bending resistance, and the control of the inclined section bearing capacity is based on the principle of equivalent shear resistance [24]. In order to meet the reinforcement ratio requirements, galvanized iron wire was used in place of steel bars in the test model, with the wire cross section radius and spacing adjusted as needed.

The weight distribution of each floor of the test model was chosen to meet the similarity ratio, as shown in Table 3. In order to accurately simulate the basement backfill soil, a highdensity iron ore was placed on the floor and in the basement, and counterweights were arranged on the other floors, as shown in Figure 3.

2.3. Sensor Placement. In order to test the dynamic response and local stress state of the model, acceleration, displacement, strain, and force sensors, as well as laser displacement gauges, were installed on the test model in the locations shown in Figure 4. The two laser displacement gauges (LD-1/LD-2), located on the ends of the foundation slab, were used to record the vertical displacement of the slab. The four force sensors (F-1-F-4) were arranged at anchor positions of the foundation plate to measure the tension in the anchor due 
TABLE 3: Weight of each layer.

\begin{tabular}{lcccc}
\hline & \multicolumn{2}{c}{ Test model $(\mathrm{t})$} & & Prototype model (t) \\
Floor & Dead & Additional & Total & 24146.90 \\
\hline Baseplate & 7.04 & 6.93 & 13.97 & 3483.35 \\
Basement & 1.45 & 0.57 & 2.02 & 3553.00 \\
1 & 1.05 & 1.01 & 2.06 & 3420.09 \\
2 & 1.03 & 0.95 & 1.98 & 2664.79 \\
3 & 0.65 & 0.89 & 1.54 & 2268.62 \\
4 & 0.66 & 0.65 & 1.31 & 39536.75 \\
Total & 11.88 & 11.00 & 22.88 & $1 / 1728$ \\
\hline
\end{tabular}

TABle 4: Test conditions.

\begin{tabular}{lcccc}
\hline Number & Code & Intensity & $\begin{array}{c}\text { Earthquake } \\
\text { wave }\end{array}$ & Peak (g) \\
\hline 1 & W1 & - & White noise & 0.06 \\
2 & F-G & Frequent & GTR & 0.1 \\
3 & F-K & Earthquake & KOBE & 0.1 \\
4 & F-R & & RGB & 0.1 \\
5 & W2 & - & White noise & 0.06 \\
6 & ME & Moderate & GTR & 0.3 \\
7 & W3 & - & White noise & 0.06 \\
8 & RE & Rare & KOBE & 0.5 \\
9 & W4 & - & White noise & 0.06 \\
10 & DE & Destructive & RGB & 0.6 \\
11 & W5 & - & White noise & 0.07 \\
\hline
\end{tabular}

to the induced uplift of the foundation slab. The acceleration sensors and the displacement sensors were arranged along axes $\mathrm{A}$ and $\mathrm{C}$.

2.4. Test Cases. Seismic waves are applied in the direction of the short axis of the structure. When the test model reaches the nonlinear stage, irreversible plastic damage accumulation occurs. Therefore, when designing the test cases, it was necessary to simplify the selected seismic wave records, loading sequences, and loading times. In this test, the ground motion was screened according to the RG1.60 standard spectrum and calibrated by $0.5 \mathrm{~g}$. Artificial wave record RGB and two actual strong motion records, GTR and KOBE, were selected. Figure 5 shows the time history and spectrum of the input waves. The test conditions were divided into four stages: $0.1 \mathrm{~g}, 0.3 \mathrm{~g}, 0.5 \mathrm{~g}$, and $0.6 \mathrm{~g}$, constituting frequent, moderate, rare, and destructive earthquake intensities, respectively. The natural frequency of the structure after earthquake action was measured by white noise excitation. The test program and specific test conditions are shown in Table 4.

2.5. Finite Element Analysis (FEA) Model. To gain a better understanding of the dynamic behavior of the structure, three-dimensional finite element models of the test structure and the prototype structure were established by using the ABAQUS 6.10 software package. In these two models, the beam and column members were simulated by the fiber beam element (B31), and the shear wall, floor slab, and foundation plate were simulated by the layered shell element (S4R) [25]. The FEA model of the prototype structure employed the concrete plastic damage constitutive model and the bilinear kinematic hardening model. The concrete damage model assumes that the material is primarily destroyed through tensile cracking and compression crushing, and the evolution of the yield and failure surfaces is controlled by hardening variables describing the equivalent plastic tensile and compressive strain. In the test structure, gypsum was used as a material that is similar to concrete. In this study, although ABAQUS did not provide a constitutive model for gypsum, the mechanical properties of gypsum were simulated by adjusting the material properties of the plastic damage model for concrete in accordance with the results of gypsum property tests. The uniaxial compressive stress versus strain curve, uniaxial tensile stress versus strain curve, and damage coefficient of the gypsum and the prototype material are shown in Figure 6. In fact, the stress values of gypsum are much lower than that of the prototype concrete. Herein, we mainly focus on the similarity between the model material and the prototype concrete. As the foundation plate experiences uplift, nonlinear contact behavior occurs between the foundation and the structure base. The connections between the bottom of the model and the basis are shown in Figure 1. To simulate this interface in FEA, nonlinear connections with large compressive stiffness, but no tensile force, were used. The positions of the nonlinear connections are shown in Figure 7. Additionally, Rayleigh damping was used in the numerical analysis with an initial damping ratio of $5 \%$.

In order to verify the consistence of the test and FEA models, the test model was excited by white noise to determine its natural frequency. The first-order natural frequencies of the test model and of the corresponding FEA model, with no additional weights, were $15.2 \mathrm{~Hz}$ and $14.0 \mathrm{~Hz}$, respectively, with an error of $7.9 \%$. The natural frequencies of the first and second orders of the test model with additional weights were $7.5 \mathrm{~Hz}$ and $17.94 \mathrm{~Hz}$, respectively, whereas those of the corresponding FEA model were $7.64 \mathrm{~Hz}$ and $17.24 \mathrm{~Hz}$, respectively, resulting in first-order and second-order errors of $1.9 \%$ and $3.9 \%$, respectively. This demonstrates that the test FEA model is in good agreement with the test model. The natural frequencies of the first and second orders of the prototype 


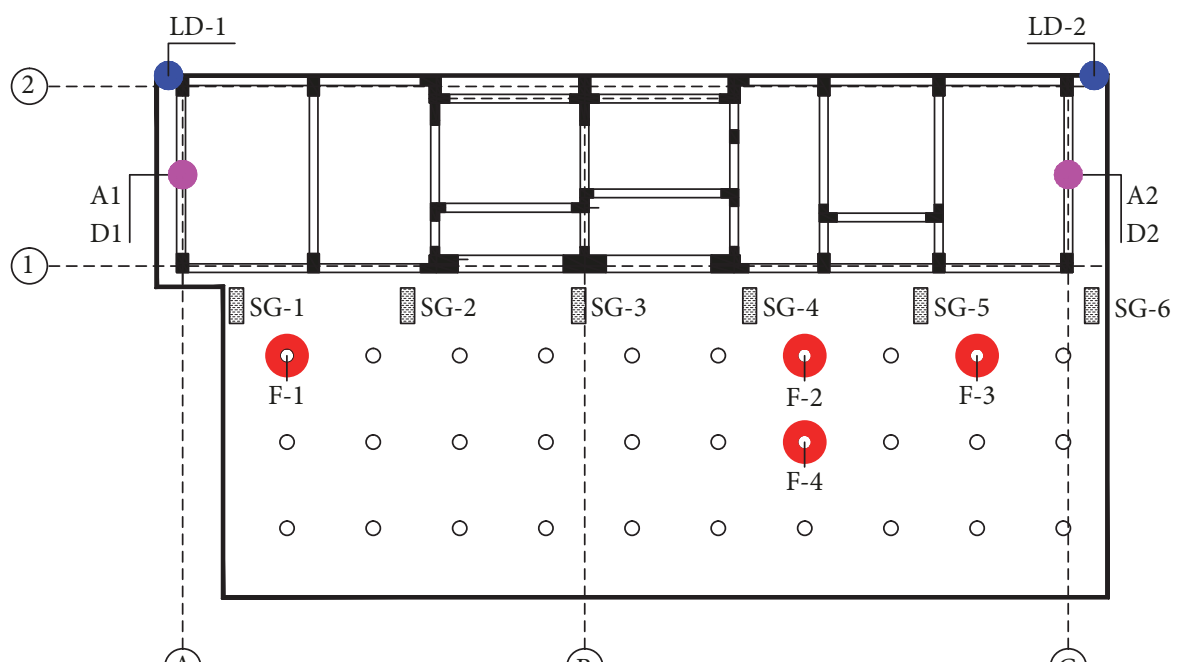

(A)

(B)

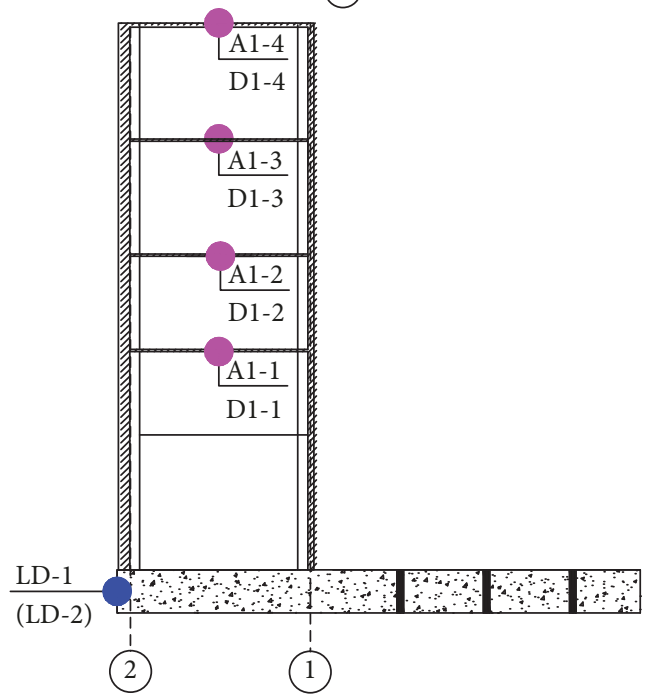

A: acceleration sensor

D: displacement sensor

SG: strain gauge
F: force sensor

LD: laser displacement sensor

FIGURE 4: Layout of sensors.

structure FEA model were $2.21 \mathrm{~Hz}$ and $5.04 \mathrm{~Hz}$, respectively, which was in accordance with similar relationship seen in Table 5.

\section{Results and Discussion}

3.1. Seismic Performance of Superstructure in the Test Model. The seismic performance evaluation of the first span structure in the CAP1400 nuclear power plant is provided as follows: under the action of a moderately intense earthquake $(0.3 \mathrm{~g})$, the key members of the superstructure remain undamaged and are still able to meet the requirements of elastic design; under the action of a rare-intensity earthquake $(0.5 \mathrm{~g})$, moderate damage may occur to the structural members, but the integrity of the structure is not affected. At no point does the displacement of the superstructure exceed the distance to the adjacent nuclear island facility, ensuring the safety of the nuclear island facility during a seismic event. When an earthquake occurs, the foundation slab may experience uplift, but the stress in the foundation slab should remain within the scope of elastic design, and the structure exhibits good antioverturning capacity. The seismic performance of the nuclear power plant is further analyzed and evaluated in this section using its structural dynamic response and the damage phenomenon observed in the shaking table tests and numerical simulations.

3.1.1. Natural Frequency. From the test results, the natural frequency change curve is shown in Figure 8 . The initial frequency was $7.5 \mathrm{~Hz}$ before the test, and after being subjected to three groups of frequent-intensity earthquakes $(0.1 \mathrm{~g})$ the first-order frequency of the model was reduced to $7.0 \mathrm{~Hz}$ or 93.3\% of the initial frequency. This demonstrates that the structure basically remained in an elastic state. After the being 

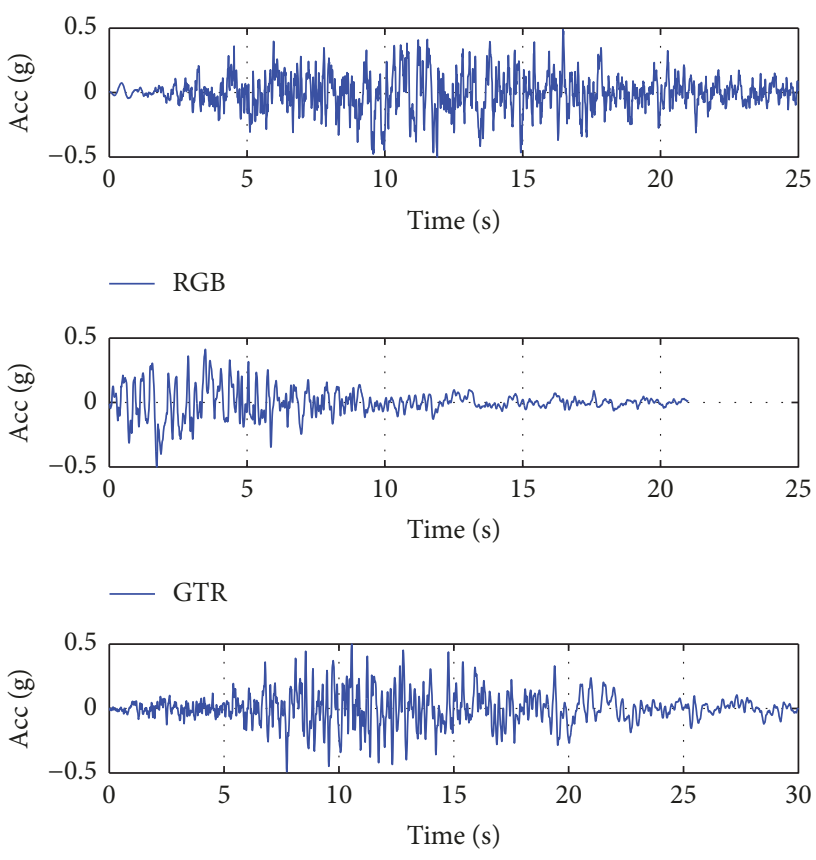

- KOBE

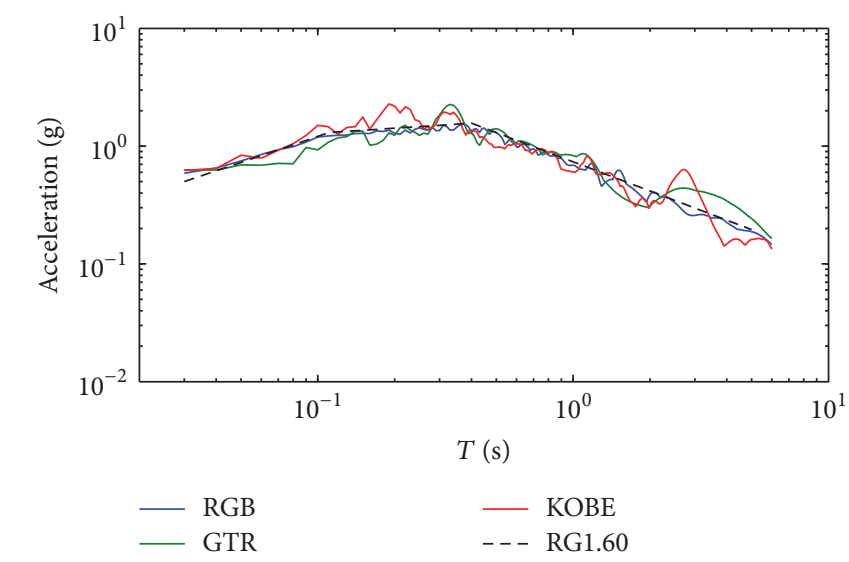

(a) Time history

(b) Response spectrum

FIGURE 5: The time history and response spectrum of applied seismic acceleration.

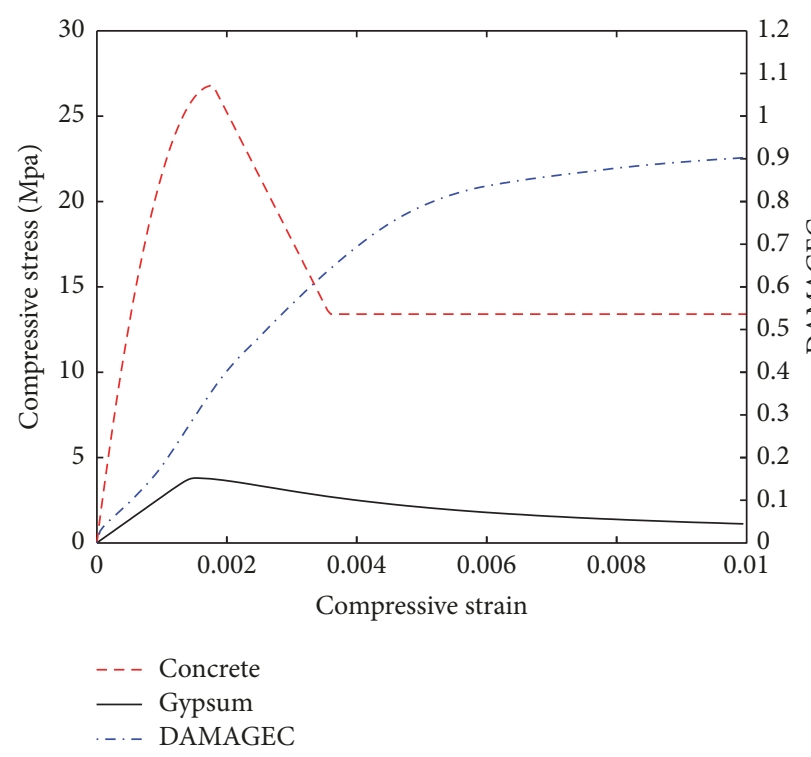

(a) Uniaxial compressive stress versus strain curve

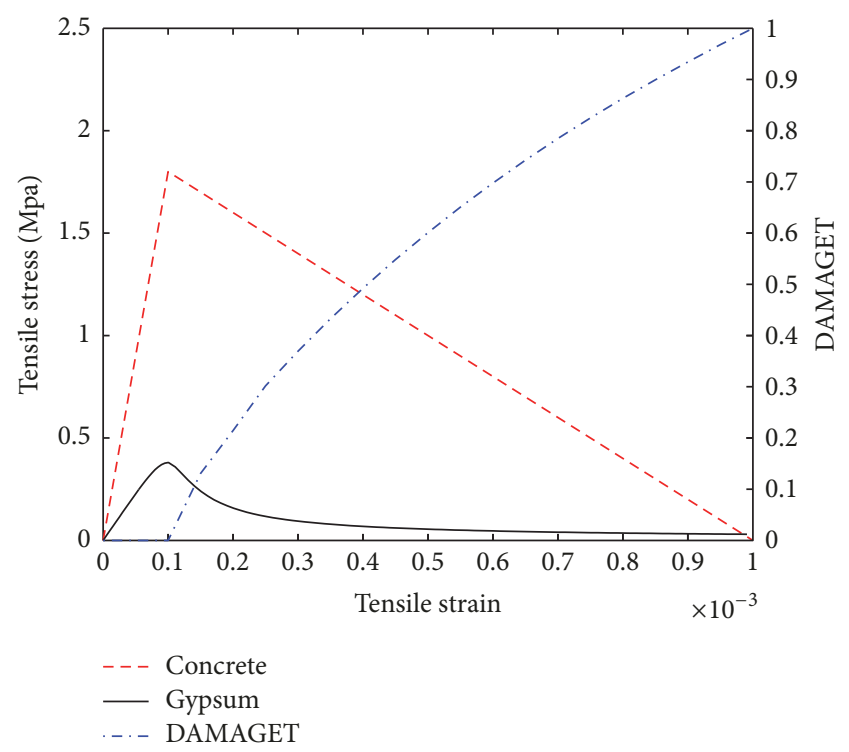

(b) Uniaxial tensile stress versus strain curve

FIGURE 6: The stress-strain relationship of the gypsum and concrete.

subjected to moderate-intensity earthquake action $(0.3 \mathrm{~g})$, the first-order frequency of the model was reduced to $80 \%$ of the initial frequency, indicating that the main members of the structure were slightly damaged, decreasing the structural stiffness. After the application of rare-intensity earthquake action $(0.5 \mathrm{~g})$, the frequency fell to $5.5 \mathrm{~Hz}$ or $73 \%$ of the initial frequency, indicating that the structure experienced significant damage, agreeing with observed test phenomena. 
TABLE 5: Structure displacement under seismic loads.

\begin{tabular}{|c|c|c|c|c|c|}
\hline \multirow{2}{*}{ Number } & \multirow{2}{*}{ Intensity } & \multicolumn{2}{|c|}{ Maximum interstory drift } & \multicolumn{2}{|c|}{ Maximum displacement at the top floor (mm) } \\
\hline & & Test & FEA & Test & FEA \\
\hline 1 & & $1 / 728$ & $1 / 625$ & 3.1 & 3.5 \\
\hline 2 & Frequent & $1 / 583$ & $1 / 562$ & 3.0 & 3.2 \\
\hline 3 & & $1 / 461$ & $1 / 581$ & 3.4 & 3.7 \\
\hline 4 & Moderate & $1 / 331$ & $1 / 171$ & 6.1 & 11.7 \\
\hline 5 & Rare & $1 / 209$ & $1 / 130$ & 6.5 & 11.1 \\
\hline 6 & Destructive & $1 / 81$ & $1 / 83$ & 13.6 & 20.7 \\
\hline
\end{tabular}

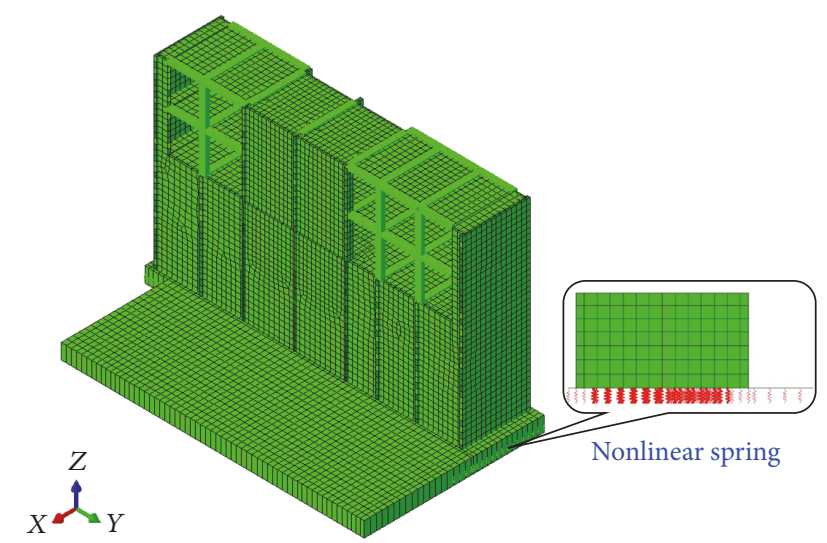

Figure 7: The FEA model of the first span.

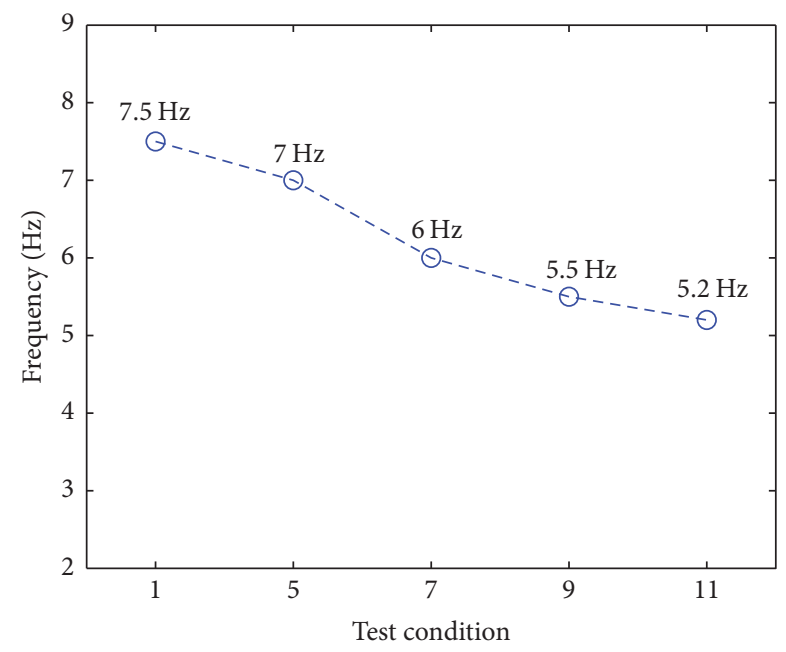

FIGURE 8: Results of natural frequency analysis.

After the application of a destructive-intensity earthquake load $(0.6 \mathrm{~g})$, the natural frequency of the structure continued to decrease to $68 \%$ of the initial frequency.

3.1.2. Acceleration Response. The amplification factor curves for the maximum acceleration of each story are shown in Figure 9, and the acceleration responses of each story in the test and numerical models are shown in Figure 10. It can be seen that the results of the numerical analysis are in good agreement with the experimental results under the same seismic conditions. The dynamic amplification factor of the structure acceleration is clearly proportional to the elevation of the story. Under the condition of frequentintensity earthquakes, the peak amplification factors for the acceleration of the top story of the structure were 3.60-5.06, and after the application of rare-intensity earthquake loads the amplification factor fell to 2.98. When the peak input ground motion increased, the dynamic amplification factors of each story decreased, which can be seen by comparing the KOBE- $0.1 \mathrm{~g}$ condition to the KOBE- $0.5 \mathrm{~g}$ condition. In this comparison, the amplification factor of the top story decreased by $21 \%$.

3.1.3. Displacement Response. The maximum interstory drift of the structure under different loading conditions is shown in Table 5, in which the maximum interstory drift can be observed to occur on the top story. In the case of a frequentintensity earthquake, the experiment was in good agreement with the numerical simulation results, but under moderateintensity earthquakes and above that, the increase in severity of earthquake action results in an increase in the degree of deviation. At the same time, the experimental and numerical simulation results show that the maximum interstory drift for stories 1-3 was relatively small, but the interstory drift for the fourth story significantly increased when loading increased from frequent-intensity earthquake conditions to the final destructive-intensity earthquake condition. The middle wall of the first axis of the structure, labeled (1) in Figure 4, exhibited a strong sway with a large displacement response. This was mainly due to the relatively weak stiffness of the upper two stories of the structure. Both the experimental and numerical analysis results show that the maximum displacement at the top story under moderate or rare-intensity earthquakes is smaller, mainly due to ground motion characteristics. In general, both the numerical and experimental models basically reflect the deformation trend of the structure. Under earthquake loading, the structural stiffness of the upper story was weak enough to result in a whiplash effect. When the damage accumulation was large, the whiplash effect obviously increased, but as a whole the maximum interstory drift of the structure was within the requirements of the design. When the rare-intensity earthquake was applied, the maximum displacement of the structure was $6.5 \mathrm{~mm}$. Notably, this value is far from exceeding the distance between the nuclear island 

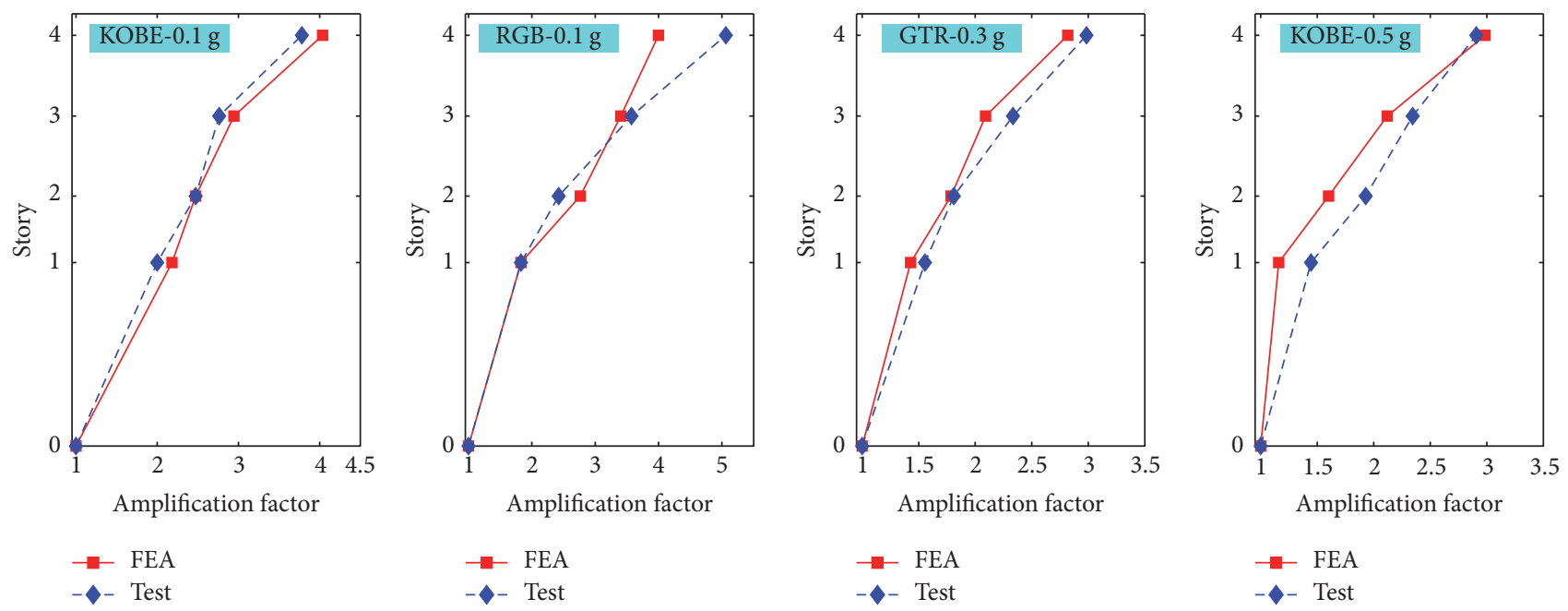

FIGURE 9: Acceleration amplification factors for different intensity earthquakes.

facility and the first span structure. Even in the destructiveintensity earthquake case the top displacement of the first span does not affect the safety of the nuclear island plant.

3.1.4. Distribution of Wall Cracks. The portion of the first span structure located on the midspan of axes (1) and (2) (as defined in Figure 4) between the third and fourth stories was severely damaged after being subjected to frequentintensity earthquakes, a moderate-intensity earthquake, and then a rare-intensity earthquake. The walls, beams, columns, floors, and joints near these locations were seriously damaged and lost integrity, as shown in Figures 11(a) and 11(b). The numerical simulation results also suggest that the tensile damage to the structure was mainly concentrated in this region, as shown in Figures 12(a) and 12(b). In the short axis direction, the shear walls on axes $\mathrm{A}$ and $\mathrm{C}$ were the main components resisting lateral force, but these shear walls are not located in the midspan of third and fourth floors. Because of this weak lateral stiffness, under earthquake action the seismic response of the midspan walls was violent, leading to the damage observed in this area. Other regions exhibiting damage include the bottom and top of the columns as shown in Figure 11(c), the end of the frame beams as shown in Figure 11(d), the interstory connections, and the peripheral area of wall holes. Note that the structural floor slabs also exhibited serious damage, though this damage is likely due to an excessively small floor thickness required by the reduced scale.

As a whole, the macroscopic phenomenon of structural damage under seismic action was basically the same as that calculated by the numerical simulation. The degree of superstructure damage was small, and the seismic performance of the overall structure was good.

3.2. Seismic Performance of the Foundation Slab in the Test Model. During the model shaking table test, the dynamic strain responses of the gypsum and iron wire in the foundation slab were measured to determine the stress state of the
TABLE 6: Strain response results for foundation slab (in $\mu \varepsilon$ ).

\begin{tabular}{lccccc}
\hline \multirow{2}{*}{ Number } & \multirow{2}{*}{ Intensity } & \multicolumn{2}{c}{ Test } & \multicolumn{2}{c}{ FEA } \\
& & Min & Max & Min & Max \\
\hline 1 & & -45 & 52 & -54 & 40 \\
2 & Frequent & -53 & 57 & -45 & 55 \\
3 & & -69 & 59 & -57 & 20 \\
\hline 4 & Moderate & -158 & 190 & -154 & 270 \\
\hline 5 & Rare & -154 & 156 & -111 & 196 \\
\hline 6 & Destructive & -242 & 246 & -250 & 250 \\
\hline
\end{tabular}

Note. Compression is negative and tension is positive.

slab. As shown in Figure 13, the strain response time history of the gypsum and iron wire is presented under three sets of conditions, in which it can be seen that the seismic responses of the gypsum and wire strain are related. The amplitudes of the dynamic strain in the iron wire, determined from the model testing and simulation under working conditions, are provided in Table 6 . An analysis of data in this table suggests that the test values are close to the simulated values, the strain amplitude of the foundation slab increases gradually with the increase in the seismic input peak, and the dynamic tensile and compressive strain at each point is symmetrical during reciprocating loading. In the case of the destructiveintensity earthquake, the maximum compressive strain in the foundation was $-242 \mu \varepsilon$, and the maximum tensile strain was $246 \mu \varepsilon$. The foundation slab of the experimental model was still in an elastic state, which can be deduced from the above strain results. During the test, no obvious cracking or other damage occurred on the foundation slab, which agreed with the strain data collected.

3.3. Overturning Resistance Analysis of the Test Model. Under the action of horizontal earthquakes, the overturning moment generated by the inertial force is resisted by the structural weight and the bending stiffness of the foundation slab. In the rare-intensity earthquake case, shown 

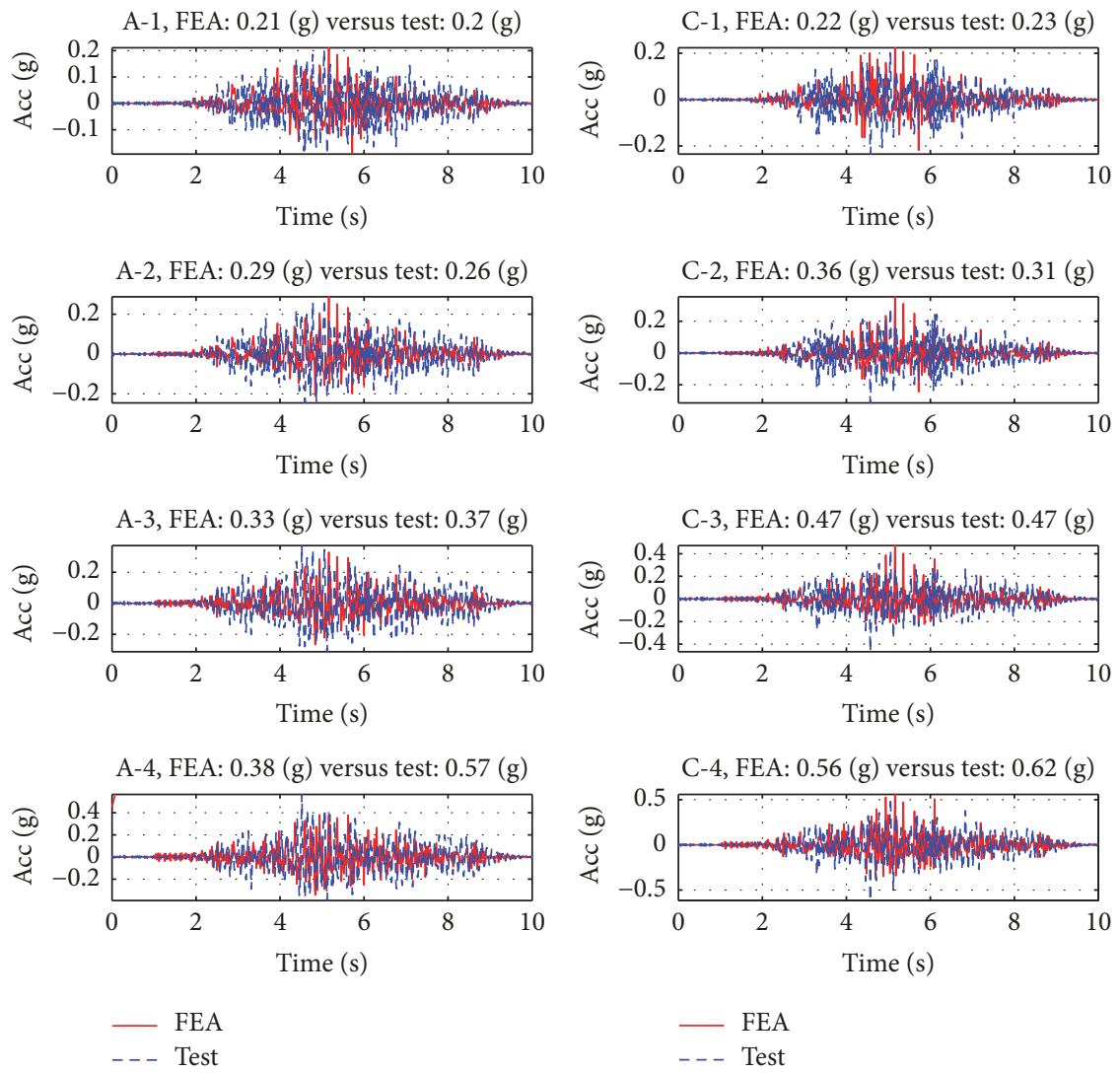

(a) RGB-0.1 g condition
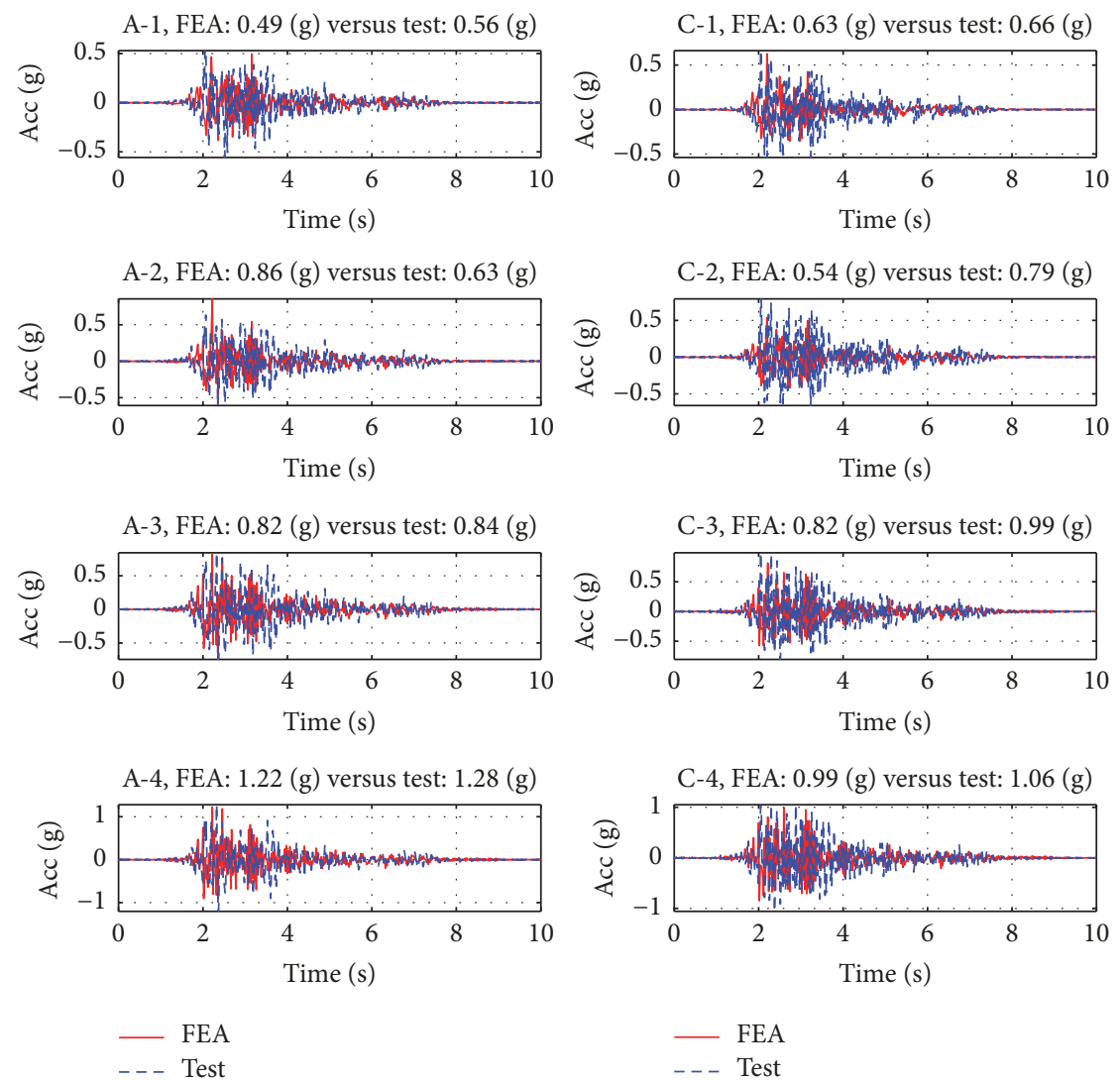

(b) GTR- 0.3 g condition

FIgURE 10: Continued. 

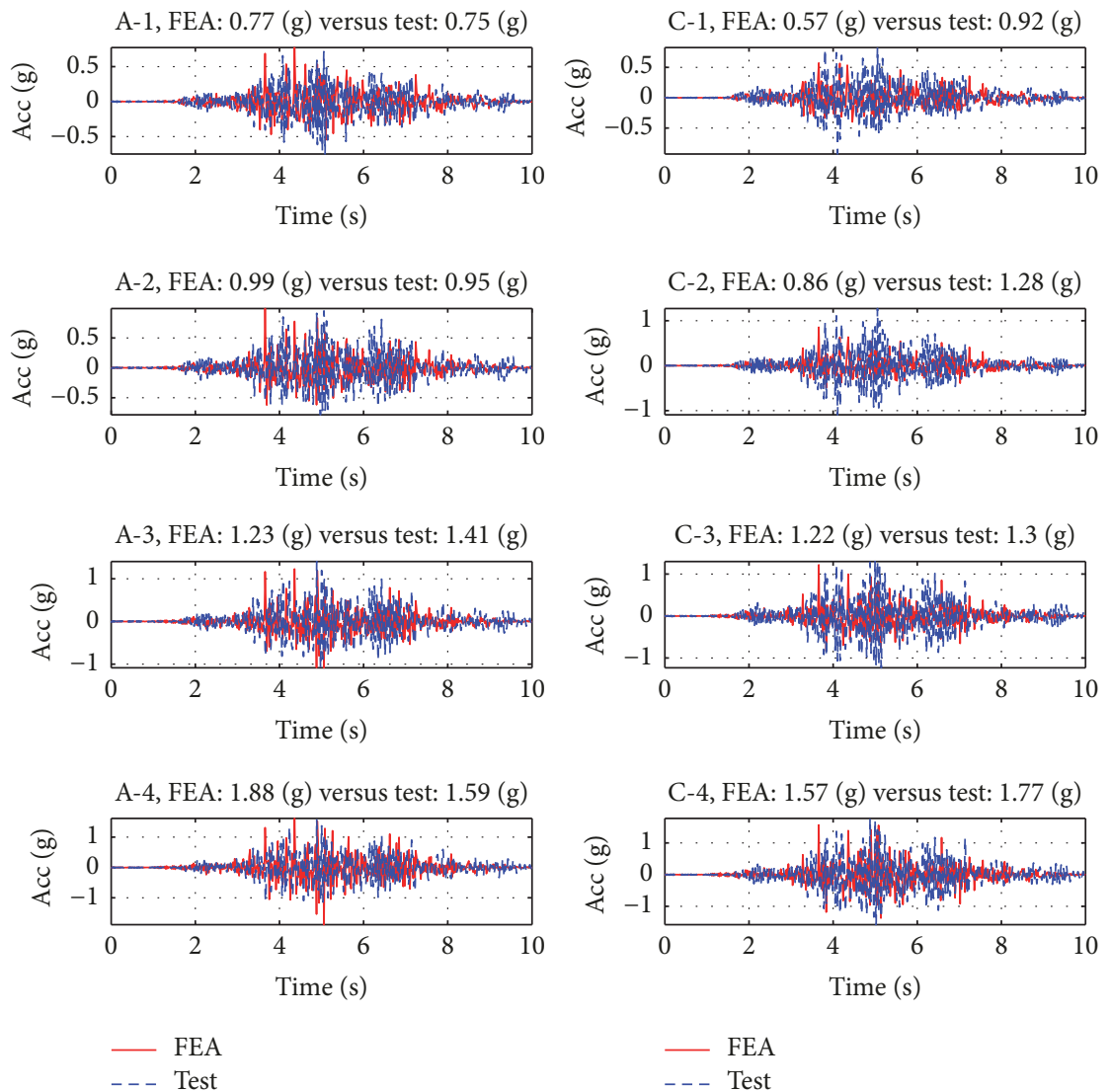

(c) KOBE- 0.5 g condition

FigURE 10: Acceleration time histories for different intensity earthquake events.

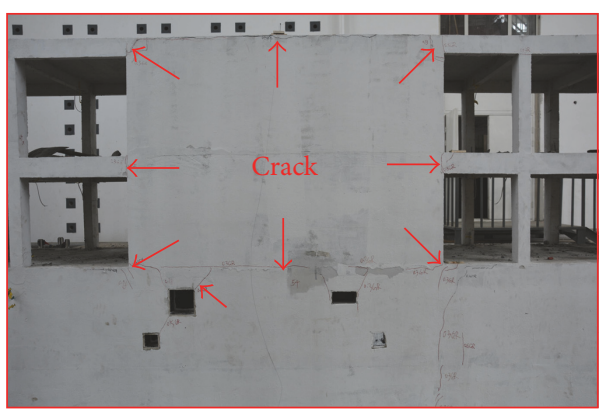

(a) The wall in axis (1)

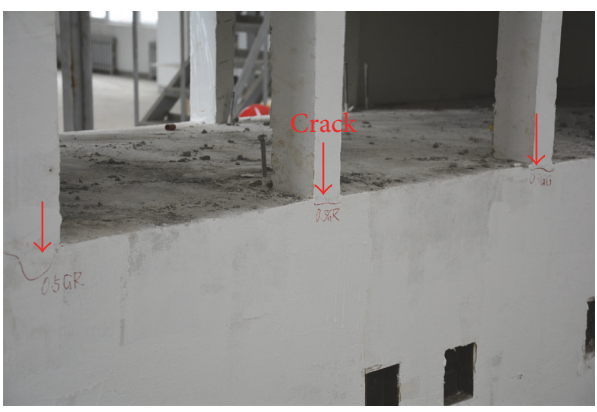

(c) The column damage

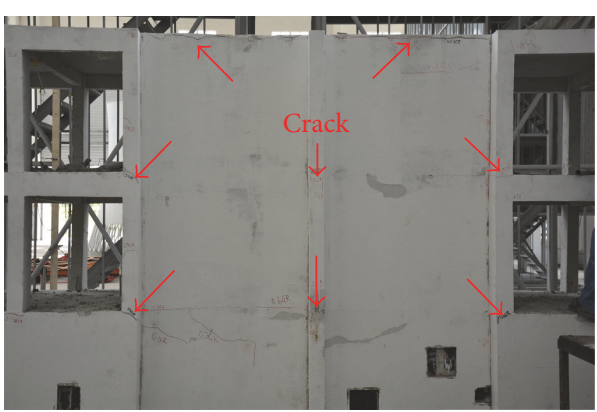

(b) The wall in axis (2)

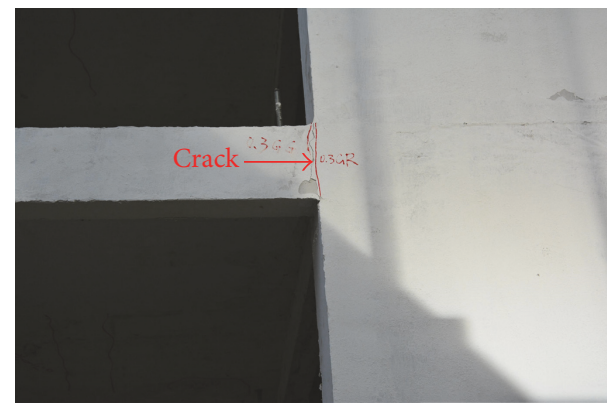

(d) The beam damage

FIGURE 11: Seismic damage to test model. 
DAMAGET

SNEG (fraction $=-1.0$ )

(Avg: $75 \%$ )
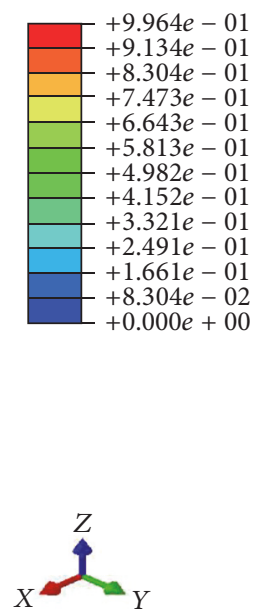

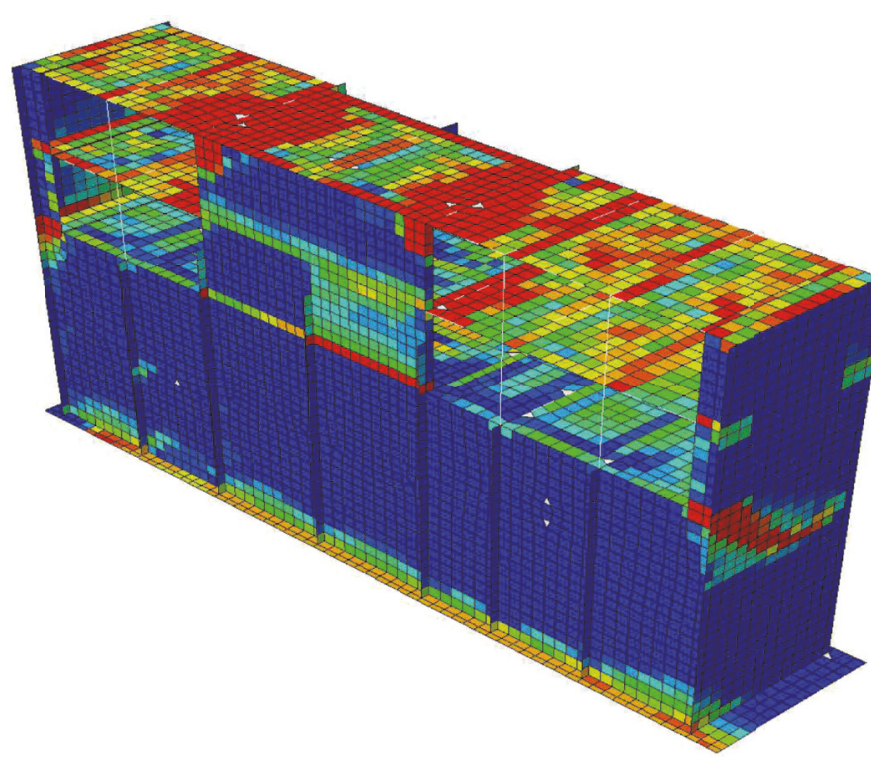

(a) Degree of tensile damage to axis (1) walls

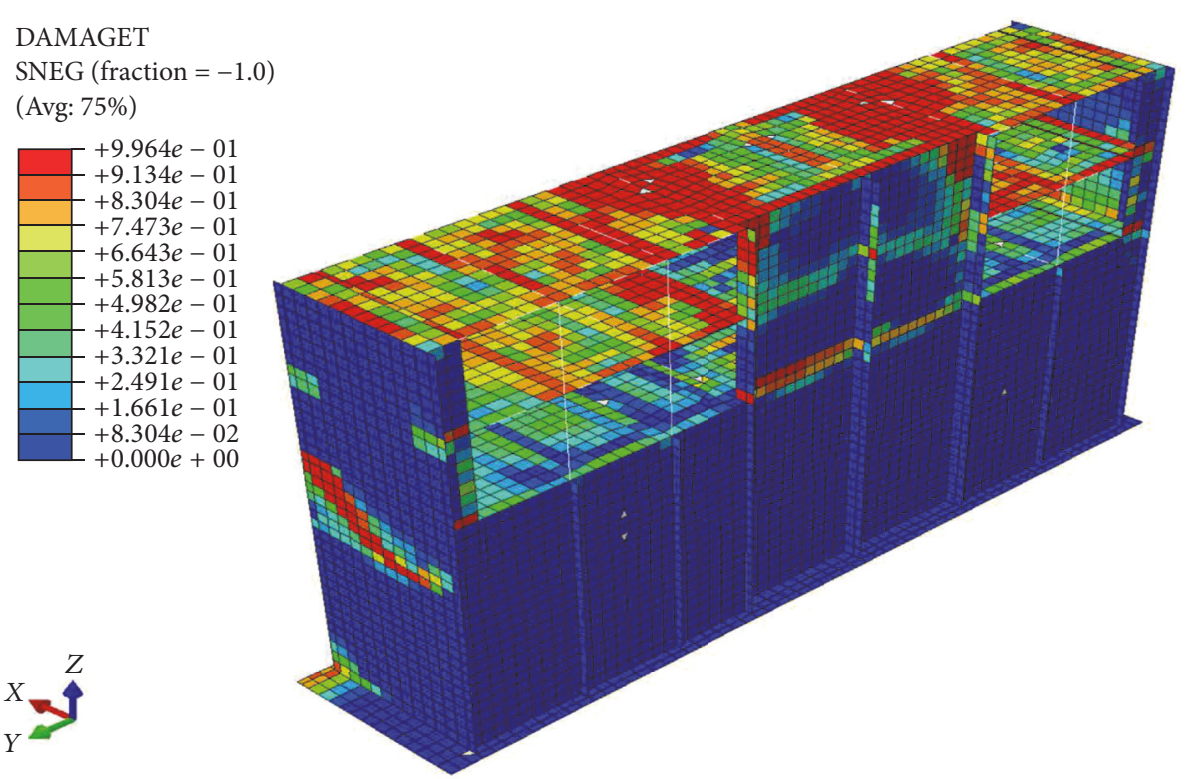

(b) Degree of tensile damage to axis (2) walls

Figure 12: Seismic damage in the FEA model.

in Figure 14, the foundation slab under the first span was observed to completely separate from the base.

The test results show that the force in the anchor bolt connecting the foundation slab and the shaking table surface varies with earthquake intensity. Figure 15 shows the measured anchor pretension (compression is negative and tension is positive) under earthquake loading. When the sensor reports compression, the foundation plate is being uplifted by the excitation.

Based on the results of the test and simulation, an assumption that the uplift force acts on the end of the anchor was made. Using this assumption, a simplified analysis and calculation model for the structure was established and is shown in Figure 16. Considering the basement, the structure model has five degrees of freedom, with the structure fixed to the foundation slab, which is located on a rigid base with one end of the slab restrained. In this model, $m$ is the structure story quality, $h$ is the structure story height, $G$ is the weight of each story, $F$ is the horizontal force in each story horizontal, and $b$ is the horizontal distance between the structure and the constraint endpoint. When the structure is subjected to seismic loading, the foundation plate is uplifted and the moment equilibrium is expressed as shown in (7), in which $x$ is the displacement due to horizontal motion, and $M_{s}$ is the bending moment in the foundation slab. Based on safety considerations, the maximum acceleration response 

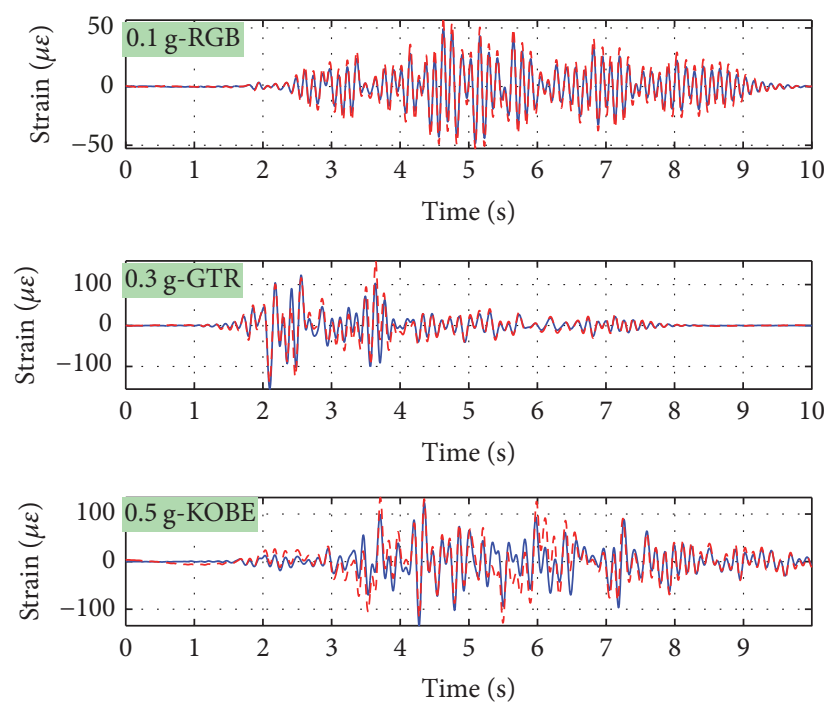

- Gypsum

FIGURE 13: Time history curve of foundation slab strain.

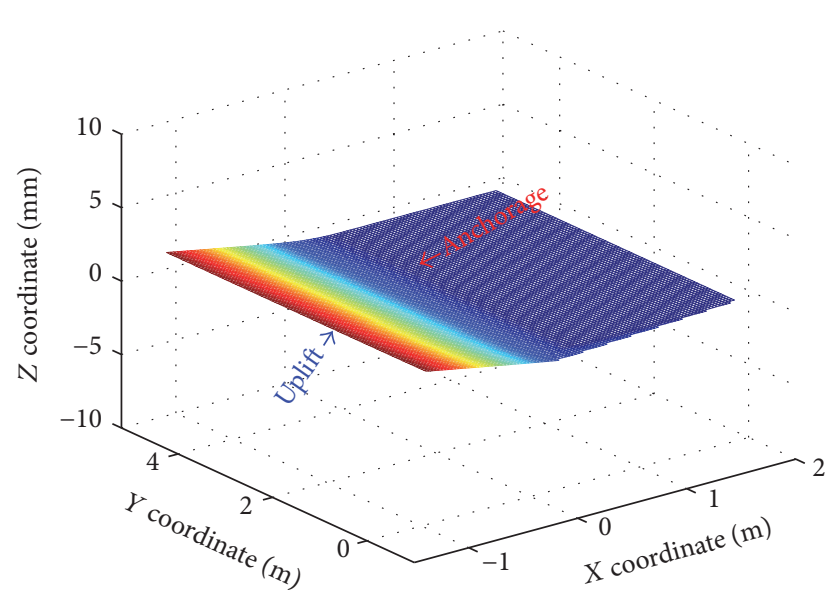

FIgURE 14: The uplifted area of the foundation plate.

of each story is taken when the horizontal inertial force is calculated, as shown in (8). In this equation, $a$ is the acceleration response of each story, and the force arm of each story is the vertical distance from each story to the foundation slab. The bending moment in the foundation slab and the bearing capacity of the foundation slab were compared using bending moment analysis, where $M_{s}$ is the bending moment in the foundation slab, and $M_{\text {design }}$ is the maximum moment provided by the bearing capacity of the foundation slab.

(1) Satisfying: $M_{s} \leq M_{\text {design }}$.

(2) Dissatisfying: $M_{s}>M_{\text {design }}$.

$$
\begin{aligned}
\sum_{n=1}^{5} G_{n}\left(b-x_{n}\right)+G_{b} x_{b}+M_{s} & =\sum_{n=1}^{5} F_{n} H_{n}, \\
F_{n} & =\max \left(a_{n}\right) \cdot m_{n} .
\end{aligned}
$$
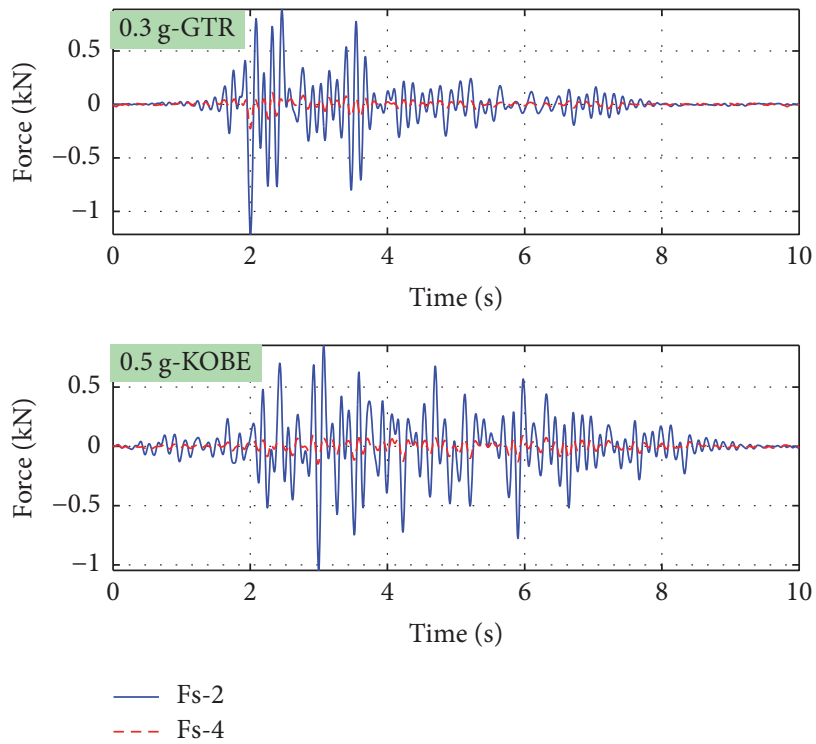

FIGURE 15: Measured pretension in slab-to-shaking table anchors.
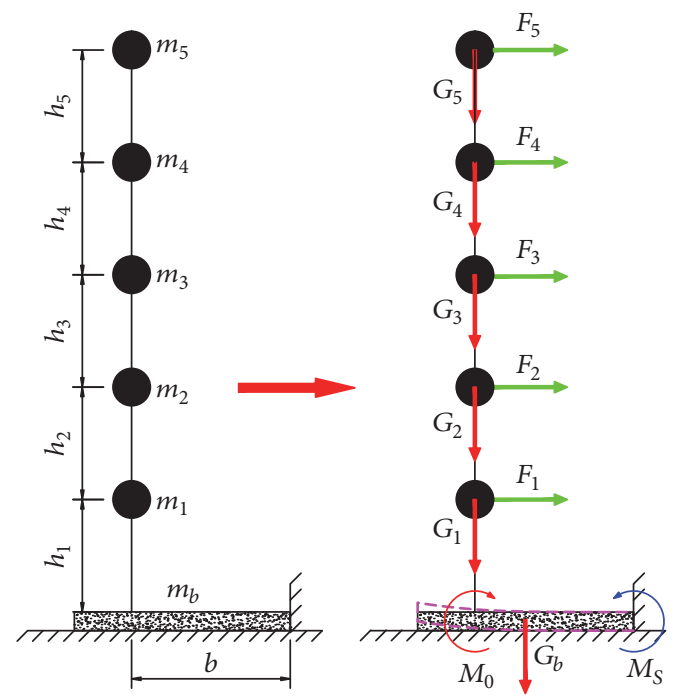

FIGURE 16: A mechanical calculation model considering foundation uplift.

The antioverturning moment produced by the structure weight was fixed at $208 \mathrm{kNm}$ as the acceleration of gravity was constant. Under the rare-intensity earthquake condition, the acceleration amplitudes of each story were determined according to the test results shown in Table 7. The total overturning moment generated by the inertial force was $226 \mathrm{kNm}$, taking into account the basement filling soil. The structure weight provided $92 \%$ of the antioverturning bending moment, with the foundation slab providing the remaining $8 \%(18.0 \mathrm{kNm})$, which was less than the design value of the slab at $76 \mathrm{kNm}$. If the foundation slab is assumed to be a cantilever beam and a bending moment of $18.0 \mathrm{kNm}$ is applied, the vertical displacement at the end of the beam is $0.49 \mathrm{~mm}$, which is close to the displacement of $0.38 \mathrm{~mm}$ 

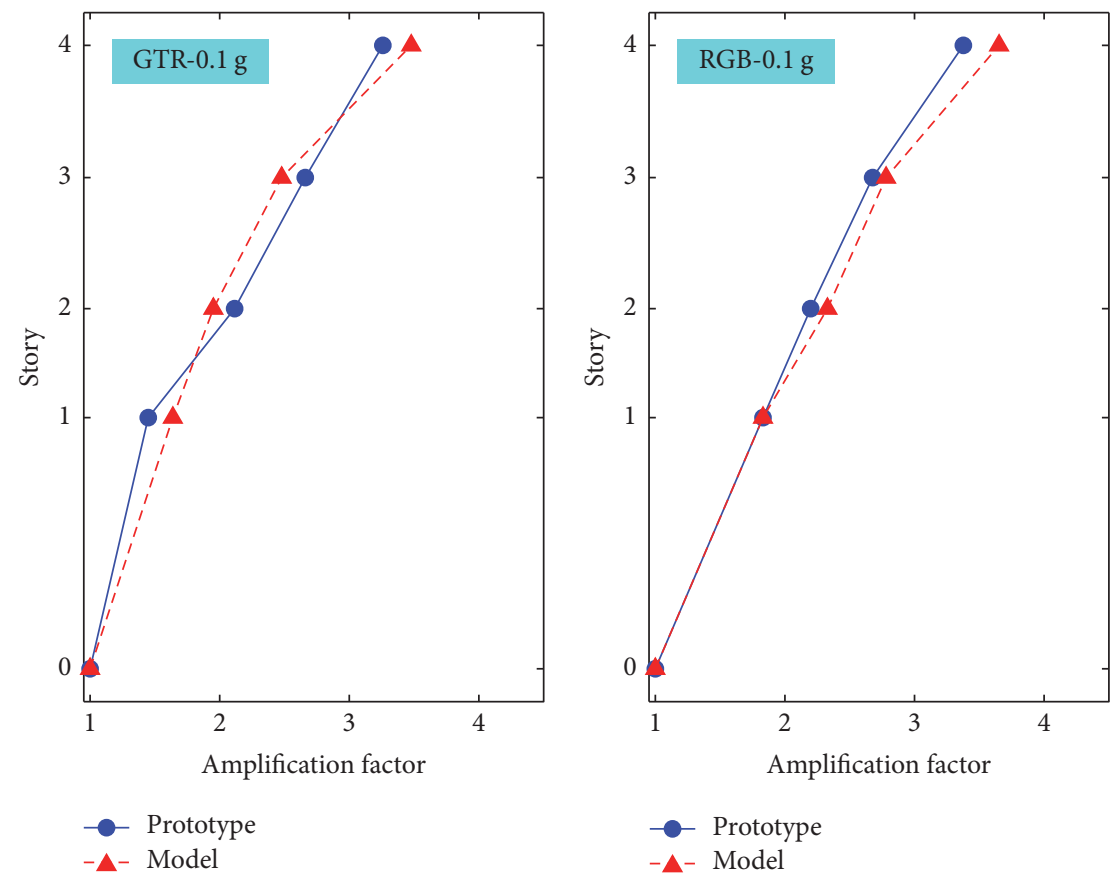

FIGURE 17: Amplification factor of the prototype structure and test model structure under frequent earthquakes.

TABLE 7: Overturning moment analysis.

\begin{tabular}{lcccccc}
\hline Story & Basement & 1 & 2 & 3 & 4 & Total \\
\hline Mass $(\mathrm{t})$ & 8.95 & 2.06 & 1.98 & 1.54 & 1.31 & 15.84 \\
Arm $(\mathrm{m})$ & 0.75 & 1.28 & 1.65 & 2.40 & 3.17 & - \\
Acceleration $(\mathrm{g})$ & 0.73 & 0.84 & 1.10 & 1.35 & 1.67 & - \\
Moment $(\mathrm{kNm})$ & 49 & 22.15 & 35.94 & 49.9 & 69.35 & 226 \\
\hline
\end{tabular}

provided by the test results. The uplift displacement of the structure gradually increases with the increase in the intensity of the seismic wave, but when the input seismic wave is as high as $0.6 \mathrm{~g}$, the maximum displacement is only $0.89 \mathrm{~mm}$. As a whole, the vertical displacement of the structure was small and the antioverturning ability of the structure was good.

3.4. Seismic Performance of the Prototype Structure. A satisfactory agreement was observed between the simulation and test results of the shaking table model. Meanwhile, time history analysis for the prototype structure FEA model was performed to gain a better understanding of the seismic performance of the building. Under the action of frequent earthquakes, the prototype structure and the test model structure were in an elastic stage, and their dynamic response results satisfied similar requirements shown in Table 1 . The acceleration dynamic response of each layer in the prototype structure and the test structure is shown in Figure 17, and its interstory drift is shown in Figure 18. The above analysis results showed that the test model structure processed by similar materials could reflect the dynamic characteristics and deformation modes of the prototype structure under the effect of low intensity earthquakes.
When the moderate-intensity and rare-intensity earthquakes were applied, both the prototype structure and the experimental model structure showed different structural damage. The gypsum material used in the experimental model and the concrete material of the prototype model difficultly met the similarity in the plastic stage. Therefore, the dynamic responses of the prototype structure and the test structure had a certain difference. However, the overall failure modes of the two structures were similar; the fourth layer of the structure was the weakest and suffered the most serious damage. The maximum interstory drift of each layer is shown in the Figure 19. It can be seen from the results that the interstory displacements of the prototype were obviously smaller than that of the experimental model. The top displacement of the first span is $112.9 \mathrm{~mm}$ and it is far from exceeding the distance between the nuclear island facility and the first span structure. The seismic performance of the structure meets the design requirements and has a higher safety margin.

In the rare-intensity earthquake case, the prototype structural foundation slab was also observed to completely separate from the base. The stress of the foundation slab was still in the elastic state without damage. Overall, the bearing capacity of the foundation slab in the prototype structure could meet the requirements of seismic design.

\section{Conclusions}

In the CAP1400 nuclear power plant, the first span structure arrangement is unique, leading to the occurrence of uplift under earthquake action. As a critical engineering structure in the nuclear power plant, the seismic safety of the first span is very important. In this paper, the seismic performance of the first span structure under earthquake loading is tested 

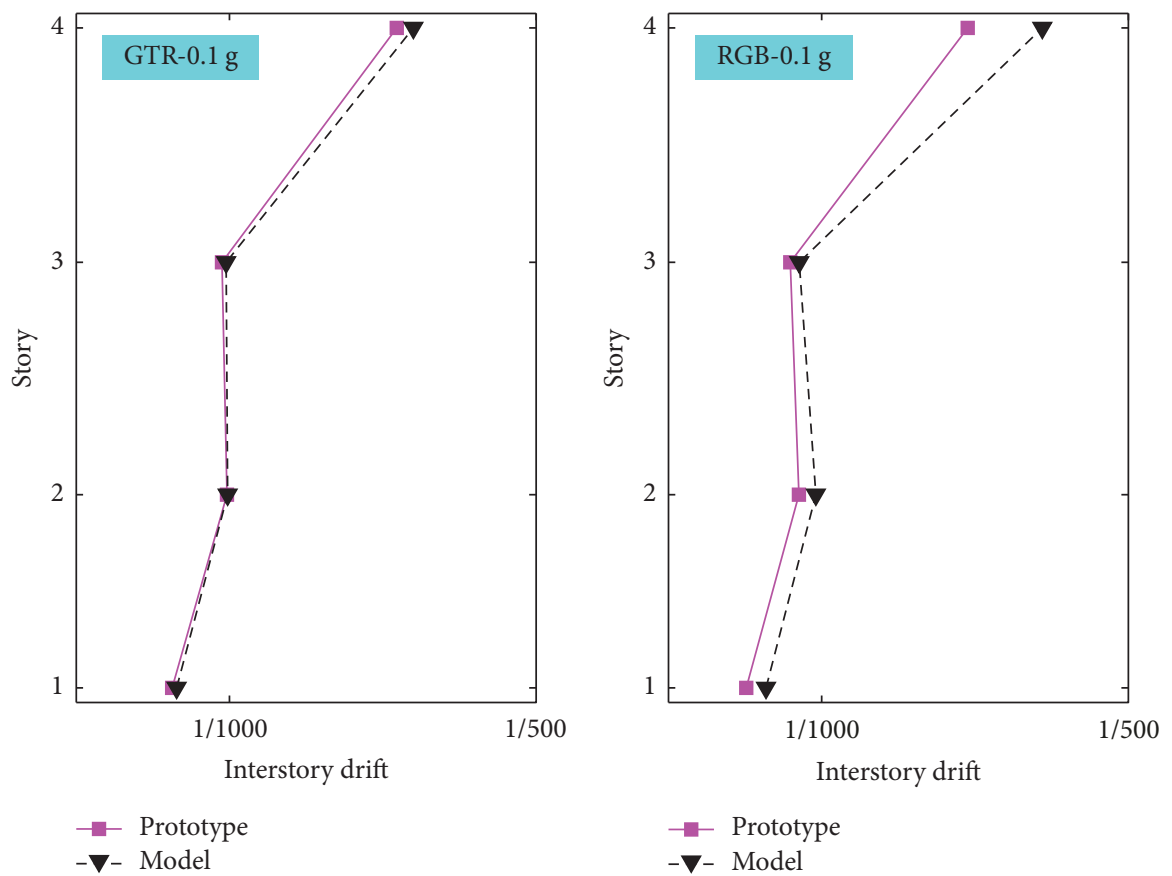

FIGURE 18: Interstory drift of the prototype structure and test model structure under frequent earthquakes.
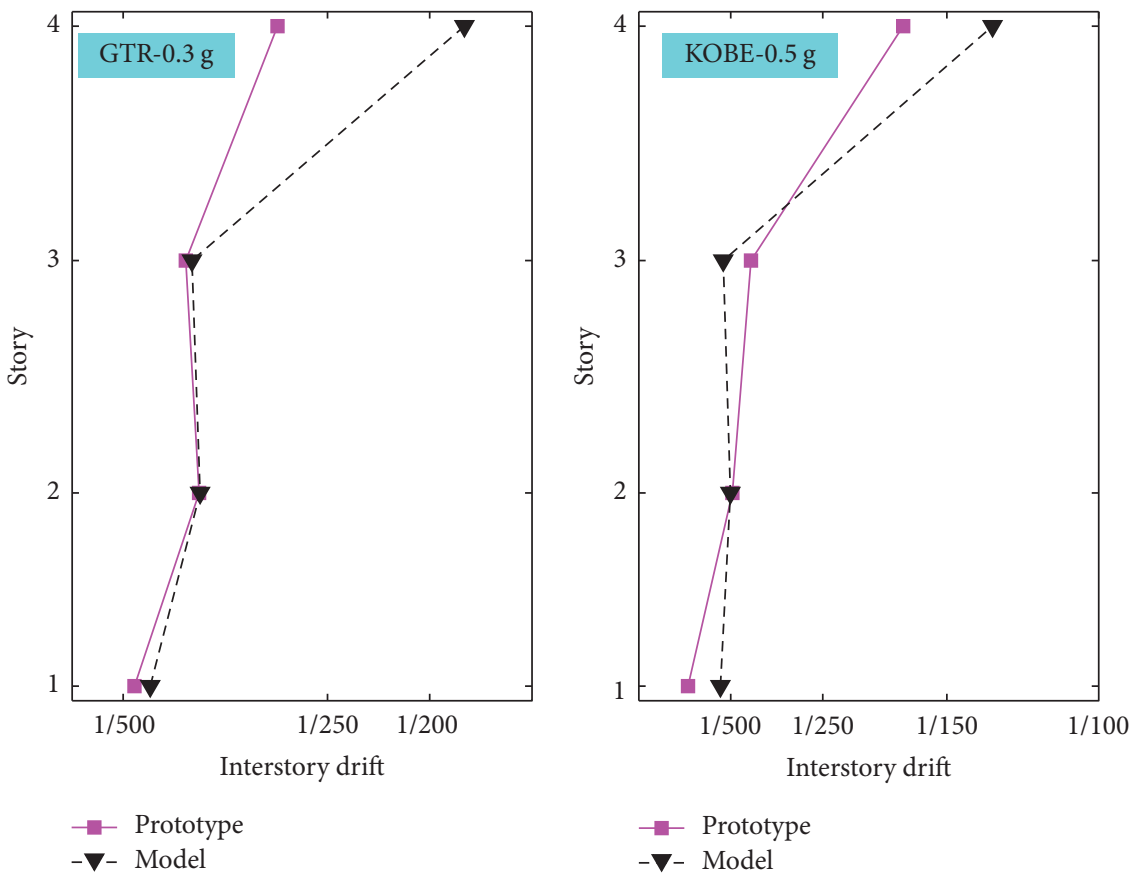

FIGURE 19: Interstory drift of the prototype structure and test model structure under moderate and rare earthquakes.

using both shaking table tests and numerical simulations, obtaining the following conclusions.

(1) Under different severities of ground motion, the foundation of the first span structure was observed to slightly detach from the shaking table. Gravity provides the main antioverturning moment, while the foundation slab remains in an elastic state and resists only a small amount of the overturning moment. The overall overturning resistance of the structure is shown to meet the relevant design requirements.

(2) With respect to the structural dynamic response and failure mode, the results of the finite element simulation and shaking table test are almost the same, which indicates that the numerical analysis model and method applied in this 
study are generally satisfactory. Numerical simulation results of the test model and the prototype structure are consistent with similar design conditions, and this shows that it is feasible to use gypsum as a material similar to concrete in shaking table tests when the structure is in an elastic response.

(3) Under the action of a moderate-intensity earthquake $(0.3 \mathrm{~g})$, the key force components of the structure remain basically intact, meeting the requirements of elastic design. Under the action of a rare-intensity earthquake $(0.5 \mathrm{~g})$, the structural stiffness decreases to a certain extent, but the structure still maintains good integrity. Under the action of $0.6 \mathrm{~g}$ ground motion, the test model is seriously damaged but does not collapse. Under no level of intensity does the displacement response of the structure affect the safety of the adjacent structure. The seismic performance of the structure is therefore shown to meet the relevant design requirements, suggesting that the scale model and numerical model approaches are able to provide a sound basis for the seismic performance design of the CAP1400 nuclear power station.

\section{Conflicts of Interest}

The authors declare that there are no conflicts of interest regarding the publication of this article.

\section{Acknowledgments}

This research was supported by the National Natural Science Foundation of China, Grant no. 51478023.

\section{References}

[1] K. Hirose, "Fukushima Daiichi Nuclear Plant accident: Atmospheric and oceanic impacts over the five years," Journal of Environmental Radioactivity, vol. 157, pp. 113-130, 2016.

[2] Y.-N. Huang, A. S. Whittaker, and N. Luco, "A probabilistic seismic risk assessment procedure for nuclear power plants: (I) Methodology," Nuclear Engineering and Design, vol. 241, no. 9, pp. 3996-4003, 2011.

[3] J. D. Stevenson, "Summary of the historical development of seismic design of nuclear power plants in Japan and the U.S," Nuclear Engineering \& Design, vol. 269, no. 4, pp. 160-164, 2014.

[4] M. Zheng, J. Yan, S. Jun, L. Tian, X. Wang, and Z. Qiu, “The General Design and Technology Innovations of CAP1400," Engineering Journal, vol. 2, no. 1, pp. 97-102, 2016.

[5] I. N. Psycharis and P. C. Jennings, "Rocking of slender rigid bodies allowed to uplift," Earthquake Engineering \& Structural Dynamics, vol. 11, no. 1, pp. 57-76, 1983.

[6] C. Yim and A. K. Chopra, "Earthquake response of structures with partial uplift on winkler foundation," Earthquake Engineering \& Structural Dynamics, vol. 12, no. 2, pp. 263-281, 1984.

[7] A. K. Chopra and S. C. Yim, "Simplified Earthquake Analysis of Structures with Foundation Uplift," Journal of Structural Engineering, vol. 111, no. 4, pp. 906-930, 1985.

[8] A. Marios, G. Gazetas, and E. Garini, "Seismic response of slender rigid structures with foundation uplifting," Soil Dynamics and Earthquake Engineering, vol. 27, no. 7, pp. 642-654, 2007.
[9] S. C.-S. Yim and A. K. Chopra, "Simplified earthquake analysis of multistorystructures with foundation uplift," Journal of Structural Engineering (United States), vol. 111, no. 12, pp. 2708-2731, 1985.

[10] A. Sinan and M. J. Dejong, "The interaction of elasticity and rocking in flexible structures allowed to uplift," Earthquake Engineering \& Structural Dynamics, vol. 41, no. 15, pp. 21772194, 2012.

[11] F. Peña, F. Prieto, P. B. Lourenço, A. Campos Costa, and J. V. Lemos, "On the dynamics of rocking motion of single rigidblock structures," Earthquake Engineering \& Structural Dynamics, vol. 36, no. 15, pp. 2383-2399, 2007.

[12] N. Makris and C. J. Black, "Uplifting and overturning of equipment anchored to a base foundation," Earthquake Spectra, vol. 18, no. 4, pp. 631-661, 2002.

[13] A. S. Koh, P. D. Spanos, and J. M. Roesset, "Harmonic rocking of rigid block on flexible foundation," Journal of Engineering Mechanics, vol. 112, no. 11, pp. 1165-1180, 1986.

[14] Y. Ishiyama, "Motions of rigid bodies and criteria for overturning by earthquake excitations," Earthquake Engineering \& Structural Dynamics, vol. 10, no. 5, pp. 635-650, 1982.

[15] C. Xu and C. C. Spyrakos, "Seismic analysis of towers including foundation uplift," Engineering Structures, vol. 18, no. 4, pp. 271278, 1996.

[16] M. Salehi, A. H. Jafarieh, and M. A. Ghannad, "Effects of foundation uplift on the dynamic response of steel frames," in Proceedings of the Structures Congress 2017, pp. 459-472, USA, April 2017.

[17] M. Midorikawa, T. Azuhata, T. Ishihara, and A. Wada, "Shaking table tests on seismic response of steel braced frames with column uplift," Earthquake Engineering \& Structural Dynamics, vol. 35, no. 14, pp. 1767-1785, 2006.

[18] China Ministry of Construction, Code for seismic design of nuclear power plants (GB 50267-97), 1998.

[19] Design Response Spectra for Seismic Design of Nuclear Power Plants, Regulatory Guide 1.60 (Revision 2), US Nuclear Regulatory Commission, Washington D.C., USA, 2014.

[20] X. Y. Yan, Y. S. Zhang, H. D. Wang, and L. S. Wei, "Experimental study on high-rise structure with three-dimensional base isolation and overturn resistance devices," Journal of Building Structures, vol. 30, no. 4, pp. 1-8, 2009.

[21] J. Liu, J. Kong, and X. Kong, "Shaking table model tests of concrete containment vessel (CCV) for CPR1000 nuclear power plant," Progress in Nuclear Energy, vol. 93, pp. 186-204, 2016.

[22] J. Liu, D. Zhao, and W. Wang, "Study of model material and scaling laws design of dynamic centrifuge shaking table test for a soil-structure interaction system," Yanshilixue Yu Gongcheng Xuebao/Chinese Journal of Rock Mechanics and Engineering, vol. 31, no. 1, pp. 3181-3187, 2012.

[23] X.-M. Liu, Q. Sheng, J. Chen, W.-H. Ke, and J.-H. Yang, "Seismic shaking table test for large-scale underground cavern group (I): Proportioning test on similar materials of surrounding rock," Yantu Lixue/Rock and Soil Mechanics, vol. 36, no. 1, pp. 83-88, 2015.

[24] S. N. Huang X and H. Zhang, "Study of design method and similitude for small-scale reinforced concrete structural models," China Civil Engineering Journal, vol. 45, no. 7, pp. 31-38, 2012.

[25] ABAQUS, ABAQUS Analysis user's manual. Version 6.10, ABAQUS Inc, 2010. 


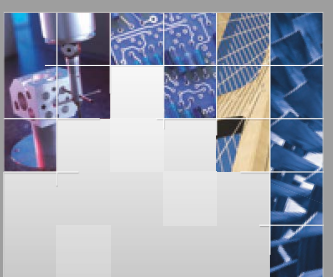

\section{Enfincering}
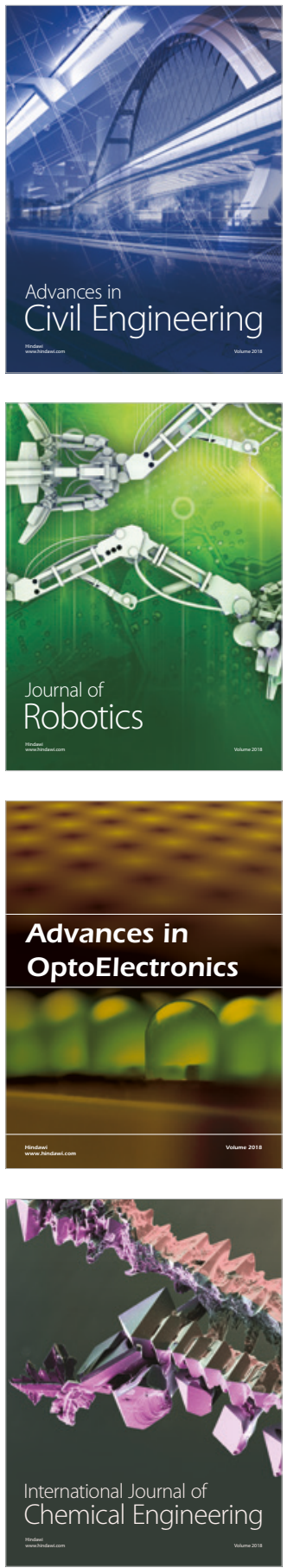

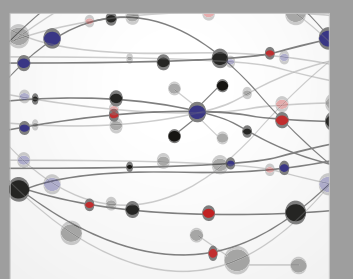

\section{Rotating \\ Machinery}

The Scientific World Journal

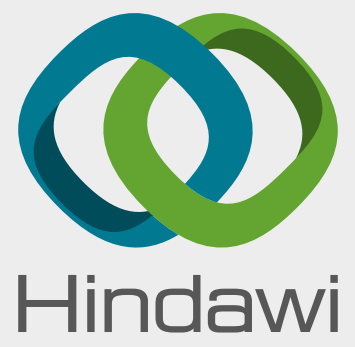

Submit your manuscripts at

www.hindawi.com
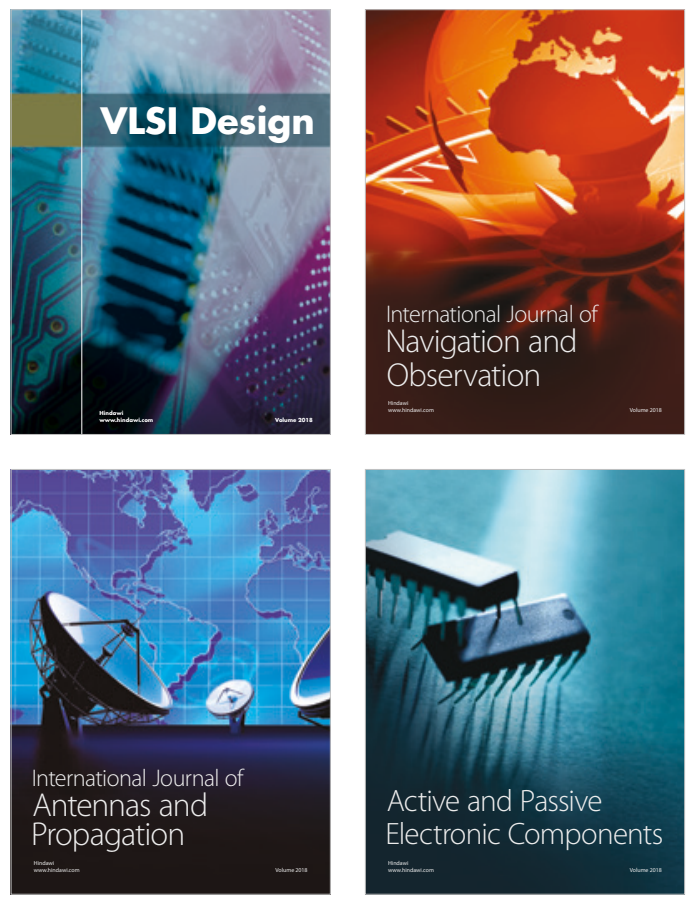
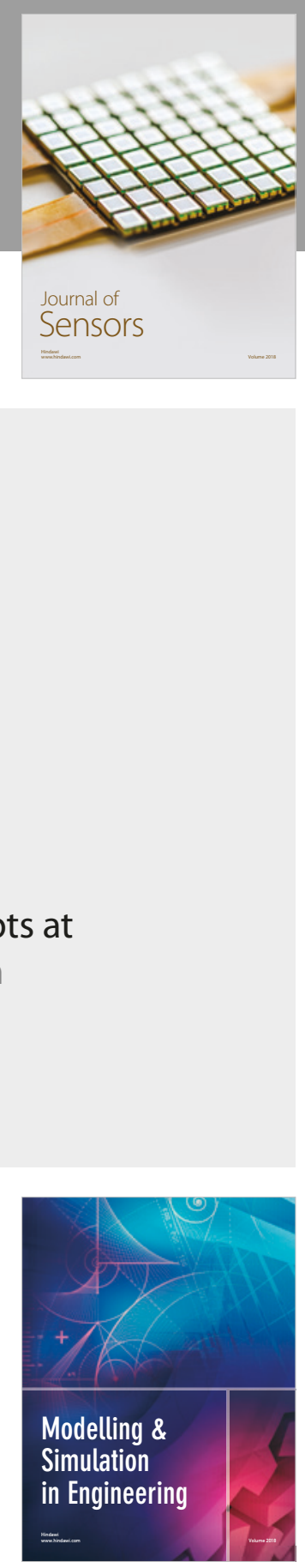

\section{Advances \\ Multimedia}
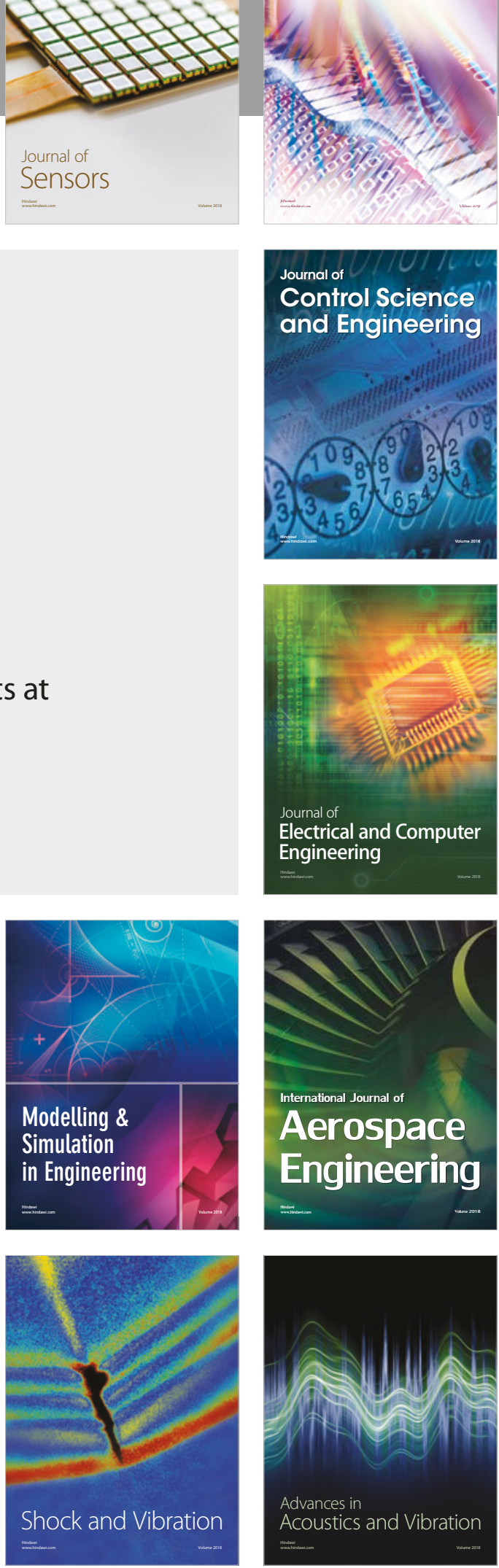